\title{
Tank Space Options Report
}

\author{
W. L. Willis and M. R. Ahrendt for \\ Washungton River Protectoon Solutions LLC \\ Richland, WA 99352 \\ U.S. Department of Energy Contract DE-AC27-08RV14800
}

$\begin{array}{lll}\text { EDT/ECN: } & \text { DRF } & \text { UC: } \\ \text { Cost Center: } & \text { 2GB00 } & \text { Charge Code. } \\ \text { B\&R Code: } & & \text { Total Pages: } 82\end{array}$

Key Words: tank, space, maxiblend faciltty, waste, alternative, slorage, concentrate, oploons, cost esiumate

Abstract. Since this report was onganally issued in 2001, several options proposed for uncreasing doubleshell tank (DST) storage space were implemented or are in the process of umplementation. Changes to the single-shell tank (SST) waste retneval schedule, completon of DST space saving options, and the DST space savung options in progress have delayed the projected shortfall of DST storage space from the 20072011 to the 2018-2025 tumefratie (ORP-1 1242, Ruver Prolection Project System Plan). Thes report reevaluates options from Rev. 0 and includes evaluations of new options for alleviating projected restretions on SST wasle retreval beginning in 2018 because of the lack of DST storage space

TRADEMARK DISCLAIMER Reference herean to any spectic commercal product, process, or service by trade name, 1radernark, manulacturex, or otheruse, does nol necessanky consotute or wnply ils endorsement, recommendabon, or lavong by the United States Gowernment ox any agency thereof or us coniractors of subcontractors

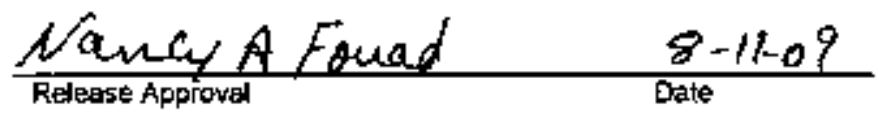

Approved For Public Release

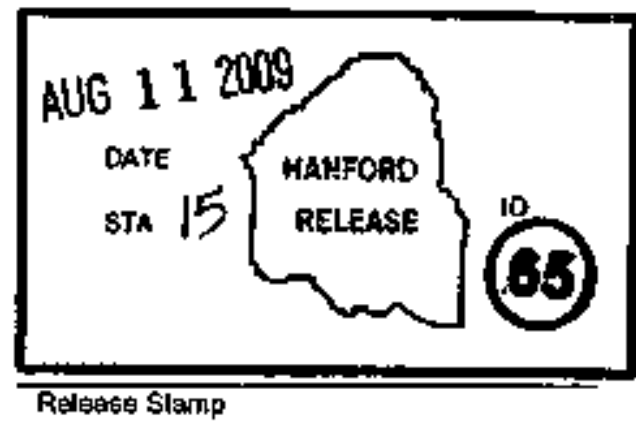




\begin{tabular}{|c|c|c|c|}
\hline \multicolumn{2}{|r|}{$\begin{array}{l}\text { Tank Operations Contractor (TOC) } \\
\text { RECORD OF REVI\$ION }\end{array}$} & $\begin{array}{l}\text { (1) Dodtument Number: } \\
\text { RPP-7702 }\end{array}$ & Page 1 \\
\hline \multicolumn{4}{|c|}{$\begin{array}{l}\text { (2) Tille: } \\
\text { Tank Space Options Report }\end{array}$} \\
\hline \multicolumn{4}{|c|}{ Change Control Record } \\
\hline \multirow{2}{*}{$\begin{array}{c}(3) \\
\text { Retísion }\end{array}$} & \multirow{2}{*}{ (4) Descripton of Change - Replace, Add, and Delelela Pages } & \multicolumn{2}{|c|}{ Authorized for Release } \\
\hline & & (5) Resp. Engr. (printifsignudate) & (6) Resp. Mgr. (print/signudate) \\
\hline I $\mathrm{Pg}$ & $\begin{array}{l}\text { Replace all pages to update evaluation of double-shell } \\
\text { tank space oplions }\end{array}$ & D. A. Tumer & 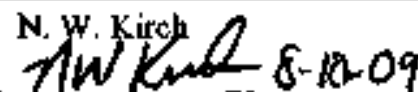 \\
\hline
\end{tabular}


RPP-7702

Revision 1

\section{TANK SPACE OPTIONS REPORT}

W. L. Willis

M. R. Ahrendt

Washington River Protection Solutions LLC

Date Published

August 2009

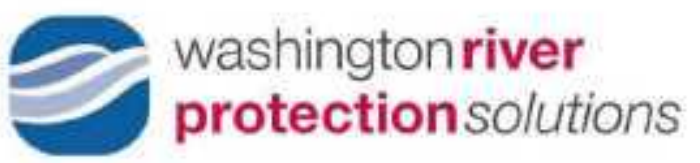

Prepared for the U.S. Department of Energy

Office of River Protection

Contract No. DE-AC27-08RV14800 


\section{EXECUTIVE SUMMARY}

Since this report was originally issued in 2001, several options proposed for increasing doubleshell tank (DST) storage space were implemented or are in the process of implementation. Changes to the single-shell tank (SST) waste retrieval schedule, completion of DST space saving options, and the DST space saving options in progress have delayed the projected shortfall of DST storage space from the 2007-2011 to the 2018-2025 timeframe (ORP-11242, River Protection Project System Plan). This report reevaluates options from Rev. 0 and includes evaluations of new options for alleviating projected restrictions on SST waste retrieval beginning in 2018 because of the lack of DST storage space.

The options implemented and those in progress include the following: (1) increasing the level of waste in AP Farm tanks, (2) eliminating dedicated operational space, (3) limiting use of restricted tank capacity, (4) combining aging waste, (5) utilizing alternative storage for emergency DST storage, and (6) concentrating waste (increasing the density of the waste to $1.43 \mathrm{~g} / \mathrm{mL}$ ). The additional DST storage space realized by implementing these options is included in ORP-11242 Revision 4. ORP-11242 indicates that DST storage capacity will be fully utilized from 2018 through 2025. Under ORP-11242, SST waste retrieval will cease in 2018 and will not resume until DST storage space becomes available in 2025 as a result of Waste Treatment and Immobilization Plant (WTP) operation.

The timely provision of additional DST storage space, or equivalent, might permit accelerated retrieval of SSTs beyond those currently scheduled for retrieval by 2018 .

This study presents options reviewed for the purpose of increasing DST storage space. Thirteen options are identified that have the potential for increasing DST storage space from about 1 million gallons up to 9 million gallons (per option), thereby potentially allowing uninterrupted SST waste retrieval during 2018-2025.

Of these 13 options, the ones deemed most likely to provide additional DST storage space in 2018-2025 are summarized in Table ES-1.

The estimated cost of implementing these options and the DST storage capacity gained varies by option. Increasing allowable DST waste levels in AN, AW and SY Farms gains approximately 1 million gallons of DST storage capacity at a cost of $\$ 5.35 /$ gallon. Concentration of DST waste to a "damp saltcake" could potentially gain up to 9 million gallons of DST storage space at a cost of $\$ 9.89 \mathrm{gallon}$. At the high end of the cost spectrum, design and construction of a waste mix/blend facility would provide 3 million gallons of new DST storage space at a cost of $\$ 122 /$ gallon. For purposes of comparison, construction of new DSTs is estimated to cost $\$ 73 /$ gallon. 
Table ES-1. Summary of Options Most Likely to Provide Additional Double-Shell Tank Storage Capacity in 2018-2025

\begin{tabular}{|l|c|c|c|}
\hline \multicolumn{1}{|c|}{ Option Title } & $\begin{array}{c}\text { Additional } \\
\text { Capacity } \\
\text { (Kgal) }\end{array}$ & $\begin{array}{c}\text { Time to } \\
\text { Implement } \\
\text { (yrs) }\end{array}$ & $\begin{array}{c}\text { Cost } \\
\text { (\$/gal) }\end{array}$ \\
\hline Construct mix/blend facility & 3,000 & 7 & 122.00 \\
\hline Raise waste levels AN, AW, and SY Farms & 990 & 1 & 5.35 \\
\hline Utilize restricted DST capacity & 733 & 5 & 16.50 \\
\hline Utilize alternative storage for DST emergency storage & 1,265 & 4 & 18.18 \\
\hline Concentrate waste to 1.43 g/mL & 3,300 & 6 & 6.97 \\
\hline Locally concentrate waste to 1.43 g/mL & 3,300 & 5 & 11.82 \\
\hline Concentrate waste to damp saltcake & Up to 9,000 & 5 & 9.89 \\
\hline Utilize waste retrieval facility surface storage for retrieved SST waste & 1,800 & 7 & 38.33 \\
\hline Utilize modular storage for retrieved SST waste & 1,000 & 4 & 29.00 \\
\hline Construct new DSTs (per tank) & 1,200 & 7 & 73.00 \\
\hline
\end{tabular}

Cost per gallon is not the only factor to consider when comparing options. A higher cost option may have the potential of significantly reducing WTP life cycle operating costs and/or immobilized high-level waste disposal costs. These cost offsets are not addressed in this report.

The results of the study are based on qualitative analyses conducted to identify promising options. The estimated costs are order of magnitude and subject to revision. Implementing some of the more promising options would represent a significant departure from the current baseline. Some of the options would diminish the operational flexibility inherent in the current baseline and increase the risk of inability to accommodate significant WTP startup problems, the potential failure of a DST, and other unforeseen events that might require additional DST storage space beyond that currently assumed necessary. The more promising options require more study to verify feasibility, upgrade cost estimates, and understand the operational impact of abnormal tank space utilization and need scenarios.

One of the options evaluated in Rev. 0 of this report, increasing allowable DST waste levels, was completed for tank 241-AP-108 and is planned but not yet implemented in the remaining AP Farm tanks. Increasing allowable DST waste levels in the remaining AP Farm tanks is no longer a planning option. ORP-11242 assumes this DST storage capacity to be available in the baseline. Raising the allowable DST waste levels in other tank farms is an option that could be pursued in the short term. Most of the remaining options require a substantial amount of time (at least several years) to implement. To make the additional DST storage space necessary for continued SST waste retrieval in 2018-2025, action to choose and implement one or more preferred options will need to be taken soon.

The timeframe for implementing a given option is driven by the nature and complexity of the option. A mix/blend facility would require time to get the necessary approvals and regulatory permits, obtain funding, and complete facility design, construction, and commissioning. Evaporating waste in the DSTs to a "damp saltcake" and consolidating "damp saltcake" waste in selected DSTs would require a significant technical study effort to verify the feasibility of the process. The study effort would include demonstrating that buoyant displacement gas release 
events can be avoided, that "damp saltcake" can subsequently be retrieved from DSTs, and that impacts of storing "damp saltcake" in DSTs poses no unacceptable operational problems. Storing retrieved SST waste in new modular surface storage facilities would require time to improve the ability to retrieve "dry" waste, obtain regulatory permits, design and construct storage facilities, and procure waste transportation casks and tanks.

Because some of the options require several years to implement, failure to make a decision in the near term may eliminate the possibility of implementing a promising option because of project schedule. The DST space needed to support SST waste retrieval operations depends on the overall objectives and priorities of the U.S. Department of Energy, Office of River Protection. Accelerating the retrieval of SST waste beyond the current planning baseline, and/or continuing retrieval of SST waste during 2018-2025, will require significant additional DST storage space. 


\section{TABLE OF CONTENTS}

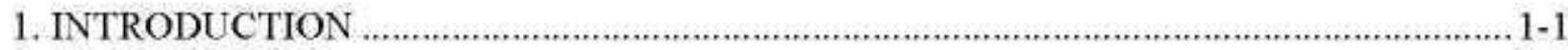

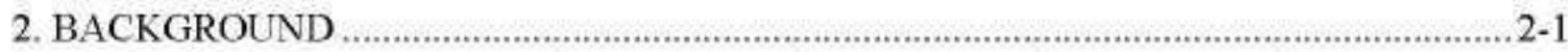

2.1 EXISTING TANK FARM FACILITIES …............................................................. 2-1

2.2 TANK CAPACITY ISSUE

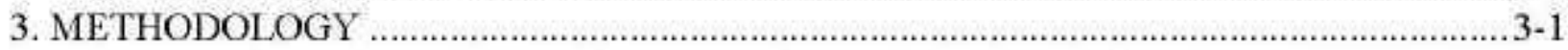

4. OPTIONS EVALUATED WITH HIGHEST POTENTIAL TO ALLEVIATE

2018-2025 TANK SPACE SHORTAGE ................................................................. 4-3

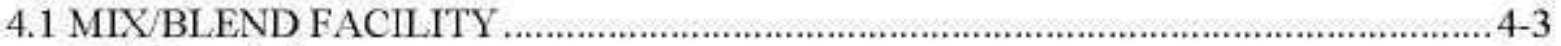

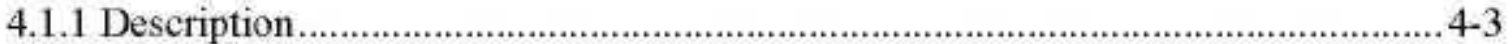

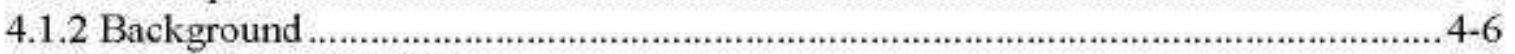

4.1.3 Evaluation of Option................................................................................. 4-8

4.2 RAISE ALLOWABLE WASTE LEVEL IN TANKS .......................................... 4-10

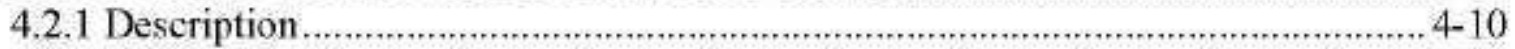

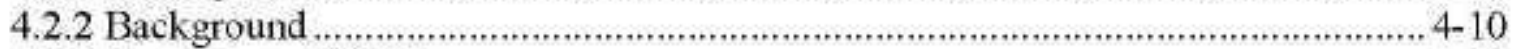

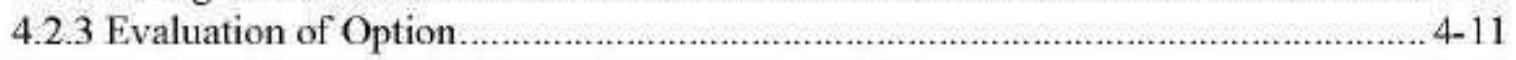

4.3 DECREASE DEDICATED OPERATIONAL SPACE …...................................... $4-14$

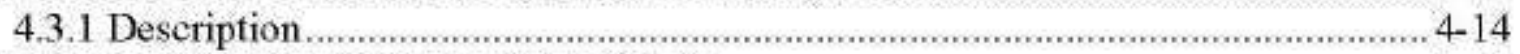

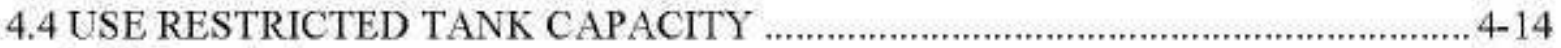

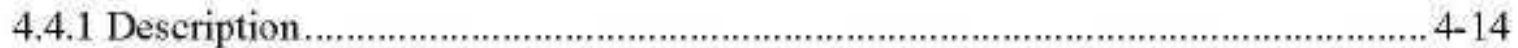

4.4.2 Evaluation of Option ............................................................................... 4-15

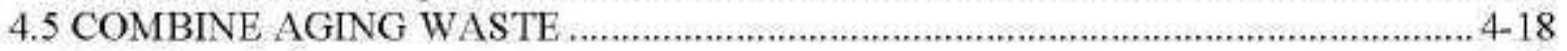

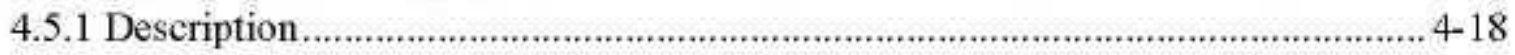

4.6 USE ALTERNATIVE STORAGE FOR EMERGENCY STORAGE …................ 4-18

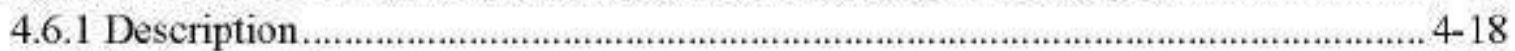

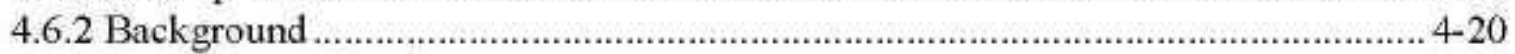

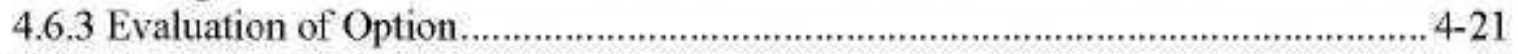

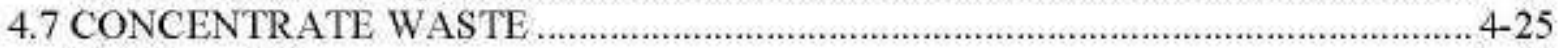

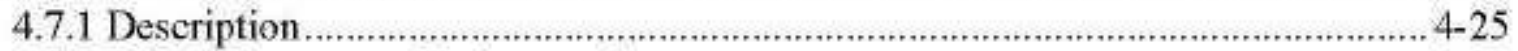

4.7.2 242-A Evaporator Background ........................................................................ 4-26

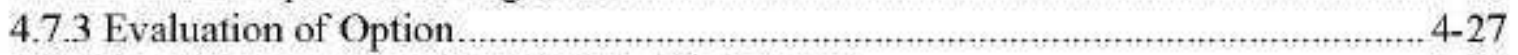

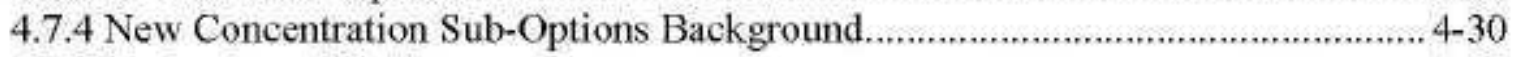

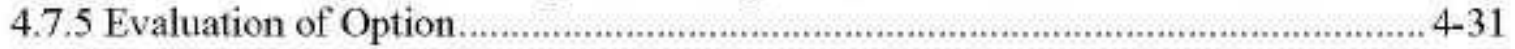

4.8 UTILIZE DOUBLE-CONTAINED SURFACE STORAGE …................................... 4-37

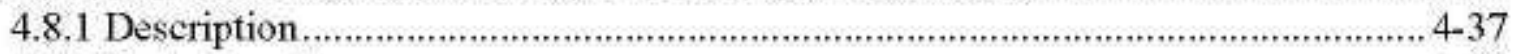

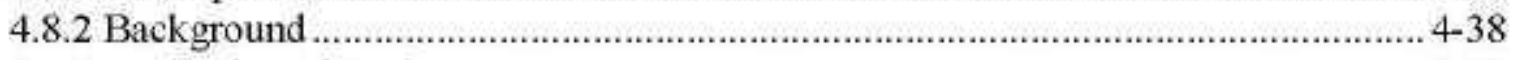

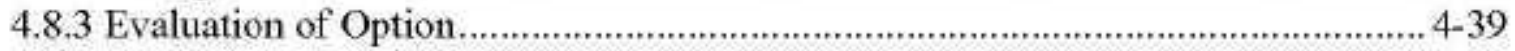

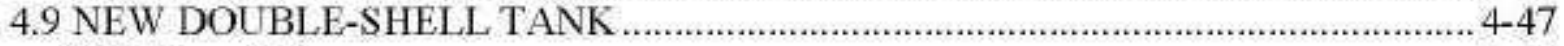

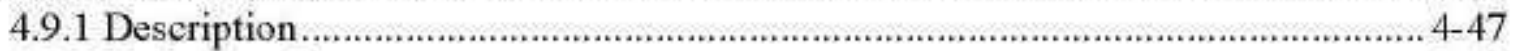

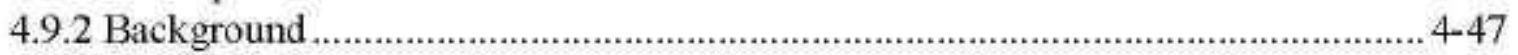

4.9.3 Evaluation of Option ............................................................................. 4-47

4.10 CONSOLIDATE WASTES IN SINGLE-SHELL TANK SYSTEM …................. $4-50$

4.11 DELIST WASTE AND SHIP TO WASTE ISOLATION PILOT PLANT .............4-50

4.12 DELAY CAUSTIC ADDITION TO THE DOUBLE-SHELL TANKS …................ 4-50 
5. OPTIONS EVALUATED LESS LIKELY TO ALLEVIATE

5.1 LONG-TERM OPTIONS TO STORE AND/OR TREAT OUTSIDE PRESENT SYSTEM 5-1

5.1.1 Separate Nonhazardous, Nonradioactive Waste Fractions .............................5-1

5.1.2 Use of Evaporators for Chemical Reactor Space .....................................................5-4

5.1.3 Deploy Low Volume Capacity Processing Units .....................................................5-5

5.2 OPTIONS EVALUATED AND DETERMINED TO BE NONVIABLE $\ldots \ldots \ldots \ldots \ldots \ldots . . . . . . .5$

5.2.1 Place Liners In Single-Shell Tanks................................................................5-9

5.2 .2 Postpone Deactivation Of Facilities ....................................................................

5.2.3 Use Existing Facilities at Energy Northwest .................................................. 5-10

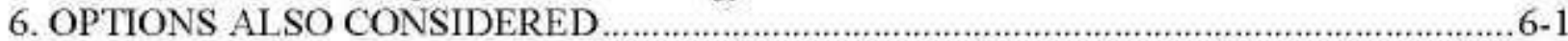

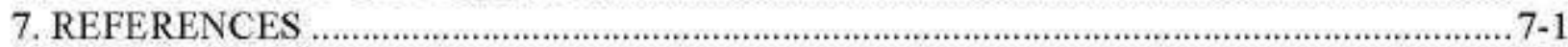

APPENDIX A: LIFE CYCLE TRANSPORTATION AND DISPOSAL COST FOR HIGH-

LEVEL WASTE CANISTERS ................................................................................. A-1

\section{List of Figures}

Figure 2-1. Double-Shell Tank Present Space Allocation ......................................................2 2-3

Figure 3-1. Relationship of Physical Tank Space Options Available ..................................... 3-2

\section{List of Tables}

Table 4-1. Performance Evaluation Feasibility Criteria .................................................. 4-4

Table 4-2. Summary of Options Most Likely to Provide Additional Capacity in 2018-2025 ....4-5

Table 4-3. Cost Estimate for Mix/Blend Facility ........................................................4-8

Table 4-4. Feasibility Considerations for Mix/Blend Facility ...............................................4-8

Table 4-5. Cost Estimate for Raising Allowable Waste Levels Option ............................. 4-12

Table 4-6. Feasibility Considerations for Raise Allowable Waste Levels ............................ 4-13

Table 4-7. Summary of Altemative Storage for Emergency Reserves................................. 4-20

Table 4-8. Cost Estimate for Alternative Storage for Emergency Reserves Option - Grout

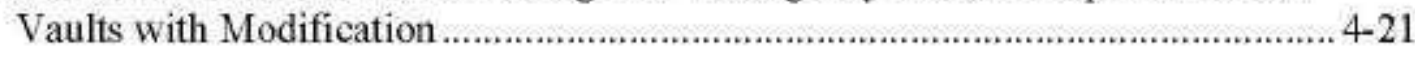

Table 4-9. Cost Estimate for Alternative Storage for Emergency Reserves Option - Grout Vaults without Modification.................................................................................. 4-22

Table 4-10. Feasibility Considerations for Utilization of Alternative Storage for Emergency Reserves Option ..................................................................................... $4-23$

Table 4-11. Cost Estimate for Concentrate Waste Option................................................ 4-28

Table 4-12. Feasibility Considerations for Additional 242-A Evaporator Campaigns Concentrate Waste Option 4-29

Table 4-13. Cost Estimate for Local Concentrate Waste Option...................................... 4-32 
Table 4-14. Cost Estimate for Dry and Consolidate Waste Option. 4-33

Table 4-15. Feasibility Considerations for Locally Concentrate Waste Option (Wiped Film Evaporator) 4-34

Table 4-16. Feasibility Considerations for Dry and Consolidate Waste Option 4-34

Table 4-17. Cost Estimate for Option 4.8A - Compliant Bladder in a Lined Basin ............. 4-40

Table 4-18. Cost Estimate for Option 4.8B - Waste Retrieval Facilities ................................. 4-41

Table 4-19. Cost Estimate for Option 4.8C - Small Modular Storage..................................... 4-42

Table 4-20. Feasibility Considerations for Option 4.7A - Compliant Bladder in a Lined Basin 4-44

Table 4-21. Feasibility Considerations for Option 4.7B - Waste Retrieval Facilities 4-44

Table 4-22. Feasibility Considerations for Option 4.7C - Small Modular Storage Tanks ...... 4-44

Table 4-23. Cost Estimate for Construct New Double-Shell Tanks Option (Based on Each One of at Least Four Tanks) 4-48

Table 4-24. Feasibility Considerations for Construct New Double-Shell Tanks Option 4-49 
RPP-7702, Rev. 1

\section{List of Terms}

BDGRE

CH-TRU

DCRT

DOE

DST

Ecology

HFFACO

HP tech

HLW

LAW

LDR

RCRA

PUREX

RH-TRU

SST

WAC

WTP

TSD

USQ

WIPP buoyant displacement gas release event

contact-handled transuranic waste

double-contained receiver tank

U.S. Department of Energy

double-shell tank

Washington State Department of Ecology

Hanford Federal Facility Agreement and Consent Order

health physics technician

high-level waste

low-activity waste

land disposal restrictions

Resource Conservation and Recovery Act of 1976

Plutonium-Uranium Extraction (plant)

remote handled transuranic waste

single-shell tank

waste acceptance criteria

Waste Treatment and Immobilization Plant

treatment, storage, and disposal

unreviewed safety question

Waste Isolation Pilot Plant 


\section{INTRODUCTION}

The Hanford Federal Facility Agreement and Consent Order (HFFACO) (Ecology et al. 1989) established a timetable for the environmental restoration of the Hanford Site. Major milestones include the retrieval of waste from the single-shell tanks (SST) and subsequent SST closure. Waste retrieved from the SSTs will be stored in the double-shell tank (DST) system prior to treatment in the planned Waste Treatment and Immobilization Plant (WTP). In 2001, projections of waste volumes resulting from the retrieval of SST waste indicated a need for additional operational storage capacity by 2007 (letter CHG-00070-64 R1, "Contract Number DE-AC27-99R114047; Waste Volume Case Studies to Support the State of Washington Department of Ecology's Request"). Changes to the SST waste retrieval schedule, completion of DST space saving options, and the DST space saving options in progress have delayed the projected shortfall of DST storage space from 2007-2011 to 2018-2025 (ORP-11242, River Protection Project System Plan). Changes to key system planning assumptions (e.g, the potential difficulty encountered in satisfactorily mobilizing and mixing DST sludge layers greater than 70 inches in depth) could have a negative impact on the beginning and duration of the projected DST space shortfall.

A brief description of the Hanford Site tank farm facilities and the delineation of the DST storage capacity issue are presented in Chapter 2 . The methodology of this study is presented in Chapter 3. The options that appear to have the greatest potential for alleviating the projected 2018-2025 tank capacity shortfall and their further definition and evaluation are presented in Chapter 4.

This revision considers the options identified in the workshops organized to support Rev. 0 of this report and includes several new options. The original workshop identified options that were unlikely to alleviate the near-term tank capacity shortfall, but with promise as long-term solutions. These long-term solutions, which could reduce the amount of new DST space necessary for retrieval of SST waste, are reviewed and described in Chapter 5. Approximately 130 options were suggested in the early phases of the Rev. 0 workshops. Some options were eliminated based on the consensus of workshop participants. The surviving options are presented in Chapter 6 for the sake of completeness. 


\section{BACKGROUND}

Waste volume projections are based on the expected WTP commissioning in 2018 and planned proeessing rates. After startup and initial operations, significant volumes of DST waste will be processed by the WTP, beginning in 2019.

Recent modeling projections indicate that all available DST space will be utilized after the retrieval of the SSTs in C, AX, and A Farms which is to be completed by 2017. In addition, 11 tanks will be emptied and shipped offsite as contact-handled transuranic waste (CH-TRU). As part of the planning basis, the WTP will provide six low-activity waste (LAW) feed receiving tanks with a total capacity of $1500 \mathrm{Kgal}$. When these tanks are available, an additional $1500 \mathrm{Kgal}$ of combined processing/receipt storage capacity becomes available, which would then be consumed by the next several SST retrievals.

This section includes a brief description of the Hanford Site tank farm facilities and describes the DST space issue.

\subsection{EXISTING TANK FARM FACILITIES}

Underground tanks comprised of steel and concrete are used for storage of hazardous radioactive waste. The waste is a byproduct of nearly 50 years of nuclear weapon material production from irradiated reactor fuel at the Hanford Site. Storage is provided by 28 double-contained DSTs with a nominal capacity of 1 million gallons (Mgal) each. Twenty-five of these tanks are located in the 200 East Area and three are located in the 200 West Area.

Waste is also stored in older SSTs, tanks with a single steel liner in concrete. There are 149 SSTs located in six tank farms in the 200 East Area and six tank farms in the 200 West Area. Of these tanks, 67 are known or suspected to have leaked.

For Rev. 0 of this report in 2001 , tanks deemed subject to potential uncontrolled increases in temperature or pressure because of the nature of their waste content were designated as "Watch List Tanks," as established by the "Wyden Amendment," Public Law 101-510, Section 3137 (1990). These tanks were restricted from receiving additional waste without the written approval of the Secretary of the U.S. Department of Energy (DOE) (Public Law 101-510, 1990). There were five DSTs and 19 SSTs in this category in 2001. The "Watch List" was closed late in 2001 after Rev, 0 was released and a new classification was developed. The tanks are classified as either flammable gas waste group A, B, or C. Flammable gas waste group A tanks are restricted from the addition of waste since the contents are deemed subject to buoyant displacement gas release events (BDGRE). Flammable gas waste group B tanks are borderline waste group A tanks to which only dilute waste can be added. Flammable gas waste group $\mathrm{C}$ tanks have no restrictions. Along with the flammable gas waste group A tanks, there are two DSTs classified as complex concentrate tanks, and addition of waste to these tanks is also restricted.

In 2001, 15 tanks had waste addition restrictions applied (letter 00-ORP-079, "Contract DE-AC06-99RL14047 - Configuration Control of Waste Feed Delivery Contents"). 
Significant resources were expended to characterize these tanks including several that have been subjected to treatability studies at the Savannah River Site and Pacific Northwest National Laboratory in preparation for processing by the WTP. At present, two DSTs are restricted because they contain complex concentrate, five tanks are restricted as flammable gas Class A tanks, and one tank 241-AY-102(AY-102) is restricted because it was identified as the WTP feed source for commissioning of the WTP.

\subsection{TANK CAPACITY ISSUE}

The total operating capacity of the 28 DSTs is $32.5 \mathrm{Mgal}$. Figure $2-1$ presents the DST space allocations. Current restrictions reduce the amount of waste that can be stored in these tanks by $2.297 \mathrm{Mgal}$, resulting in an available capacity of $30.2 \mathrm{Mgal}$. These restrictions include 1.265 Mgal of emergency reserve space; $1.032 \mathrm{Mgal}$ in the Class A, Complex Concentrate, and WTP feed source tanks.

The DST system currently stores $26.892 \mathrm{Mgal}$ of waste (HNF-EP-0182, Waste Tank Summary Report for Month Ending March 31, 2009). The DST system currently has $3.311 \mathrm{Mgal}$ of available space. Planned retrieval of the remaining SSTs in C Farm, nine tanks in A and AX Farms, and routine operational needs are projected to utilize all of the remaining available capacity of the DST system by 2018. Draft Rev. 4 ORP-11242 utilizes all remaining available space including new space generated by raising the allowable levels in tanks 241- AP-101 (AP-101), 241-AP-102 (AP-102), 241-AP-103 (AP-103), 241-AP-104 (AP-104), 241-AP-105 (AP-105), 241-AP-106 (AP-106), and 241-AP-107 (AP-107), which account for about $770 \mathrm{Kgal}$ of additional space. Draft Rev, 4 ORP-11242 also includes planned 242-A Evaporator campaigns that will reduce the DST inventory, and includes assumptions about acceptable waste configurations (e.g., DSTs with sludge layers 70 inches or less in depth). After accounting for the DST space gained by raising allowable waste levels in AP Farm and 242-A Evaporator operations, ORP-11242 shows that the DST space is over-allocated from 2018 until 2025. If the planned activities (e.g., raising allowable waste levels in AP Farm and 242-A Evaporator operations) are not completed or existing waste configurations are not manageable (e.g., DSTs with sludge layers greater than 70 inches in depth), DST space may not be available and planned SST retrievals may need to be delayed.

With the delay in the startup of the WTP, additional storage space is needed above that addressed in the Rev. 0 report to continue SST retrieval beyond 2018. The major driver for making additional storage space available is to reduce the risk posed by continued storage of waste in the SSTs. This risk is reduced as the SSTs are emptied.

Several options judged to have the highest potential to alleviate the tank space shortage have been implemented or are planned over the next few years. The increases in DST tank volume resulting from options that were implemented, or are part of the current baseline, are included in Draft Rev, 4 ORP-11242. Raising the allowable level in the seven tanks in AP Farm increases the capacity of DSTs by $770 \mathrm{Kgal}$, but because the additional capacity was assumed in ORP-11242, the action of raising the allowable level in AP Farm will not alleviate the projected DST space shortage. Failure to raise the allowable level in AP Farm tanks would result in an effective reduction in baselined DST space (would result in over-allocation of the DSTs prior to 2018 and also likely result in lengthening the over-allocation past 2025). 
Figure 2-1. Double-Shell Tank Present Space Allocation

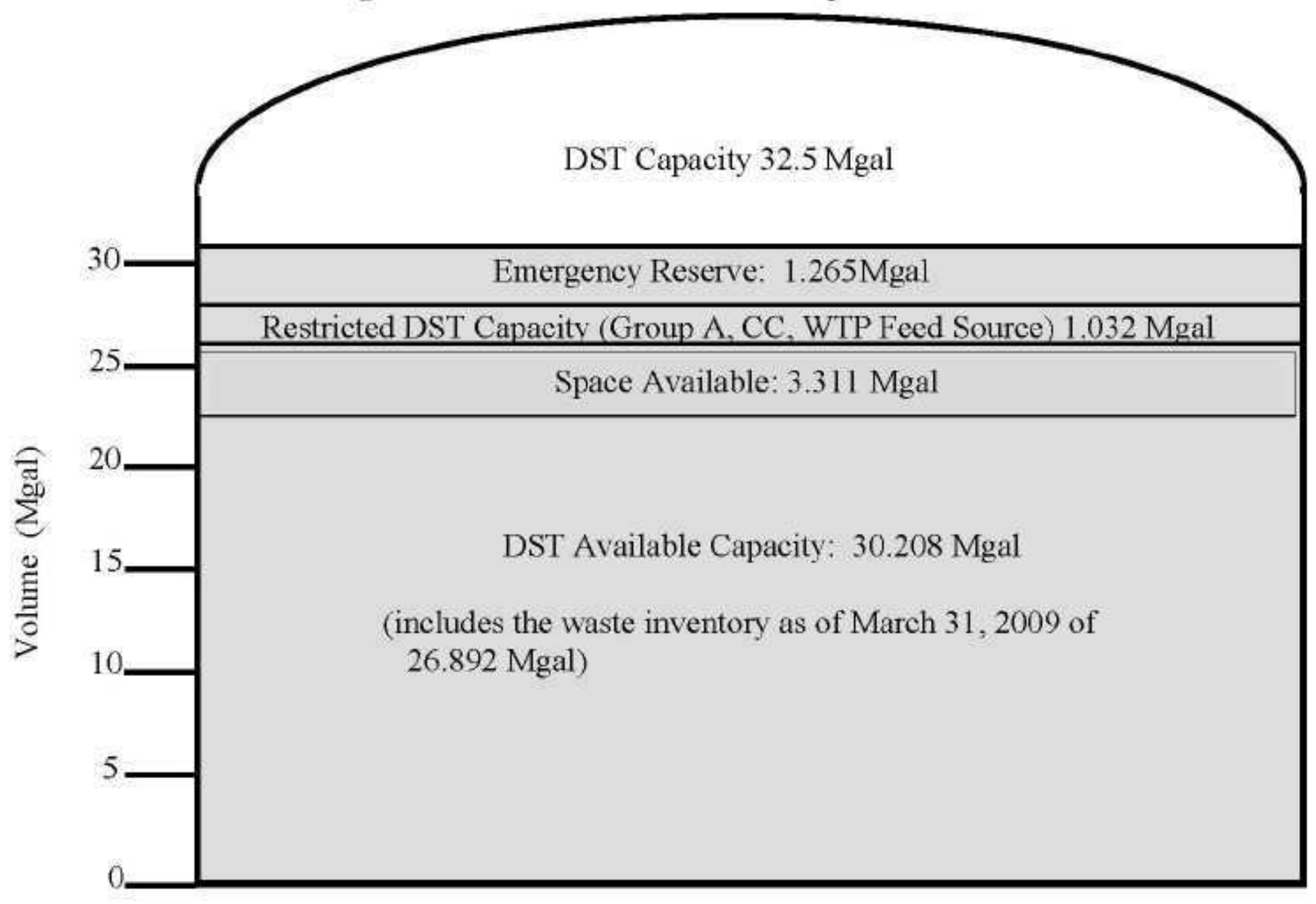


Planning for additional DST space should consider waste feed delivery and processing in the WTP. The following factors were identified in the development of this report revision:

a. The existing DSTs were not designed to mobilize settled solids (sludge or saltcake) into homogeneous slurries for waste certification prior to delivery to the WTP. The need to certify waste and to meet WTP waste acceptance criteria (WAC) requirements likely result in a need to blend high-level waste (HLW) and LAW feeds into nearly homogeneous liquids or slurries. It is anticipated that LAW feeds with low solids content can be adequately certified in and transferred from DSTs and meet the WTP requirements. Preparing HLW feeds with up to $200 \mathrm{~g} / \mathrm{L}$ solids content for certification and transfer could be problematic from DSTs. Options that provide enhanced eapability to homogenize slurries should be favored over those that do not.

b. Blending HLW would result in fewer canisters of HLW glass. Complete blending of the HLW waste would result in a total of approximately 10,300 canisters of HLW glass; whereas no blending results in approximately 16,700 canisters (an increase of about $62 \%$ ) of HLW glass (RPP-RPT-26040, Pairwise Blending of High-Level Waste). While it is clear that completely blending all $\sim 55 \mathrm{Mgal}$ of waste in a single tank is not achievable, significant benefit could likely be achieved by selective retrieval of SST waste and providing the capability of blending wastes. Options that provide or increase capability to blend waste (particularly HLW feeds) should be favored over those that do not.

c. Over $88 \%$ of the unrestricted DST capacity is currently utilized. Tank space is not currently available for activities (e.g., blending) that may optimize glass production at WTP. ORP-11242 projects that the unrestricted DST capacity will remain over-utilized until 2025. Options that provide significant storage space in a single location (e.g., empty tanks) should be favored over those that provide an equal storage space distributed over several tanks. 


\section{METHODOLOGY}

The evaluation and assessment of options for this revision of the report included a review of the options in Rev, 0 . The Rev. 0 options workshop included participants from a cross-section of individuals representing the DOE, operating contractor, and national laboratory staff. Several new options with the potential of increasing storage space were identified and are included in this revision of the report.

The evaluation of Rev. 0 of this report included the reevaluation of the less feasible options to determine if changes since 2001 might have made an option more feasible. The Hanford Tank Waste Operations Simulator modeling included in ORP-11242 shows that there will be a shortfall in DST space and additional tank space will be needed from 2018-2025 to continue retrieval of SSTs. With no additional DST storage capacity, the existing DST space is fully utilized during that time period. Opportunities that require research and development prior to implementation, but are not mature enough to support cost estimate and schedule development are evaluated (Chapter 5).

The basic criteria and attributes for option evaluation included, but were not limited to, cost effectiveness, technical feasibility, maintainability, operability, risk reduction, and implementation schedule.

Proposed options with the potential of providing additional tank space in 2018-2025 were evaluated to meet HFFACO milestone requirements. Cost estimates and schedules were developed for comparison of the options in accordance with the level of detail in the Rev. 0 report. The Rev. 0 report included preliminary cost estimates and schedules with the level of detail considered to be necessary by workshop participants. To make comparisons, this revision of the report includes the same level of detail for the evaluation criteria. The preliminary schedules of expenditures for each of the multiyear options are not budget grade and require additional review before they can be adopted as a basis for out-year planning. Results are presented in Chapter 4. Long-term solutions identified in the workshops are presented in Chapter 5. Some options were discounted as nonviable. These options are described in Chapter 6.

A diagram of the relationship between the physical options available to increase DST waste storage space is presented in Figure 3-1. 
Figure 3-1. Relationship of Physical Tank Space Options Available

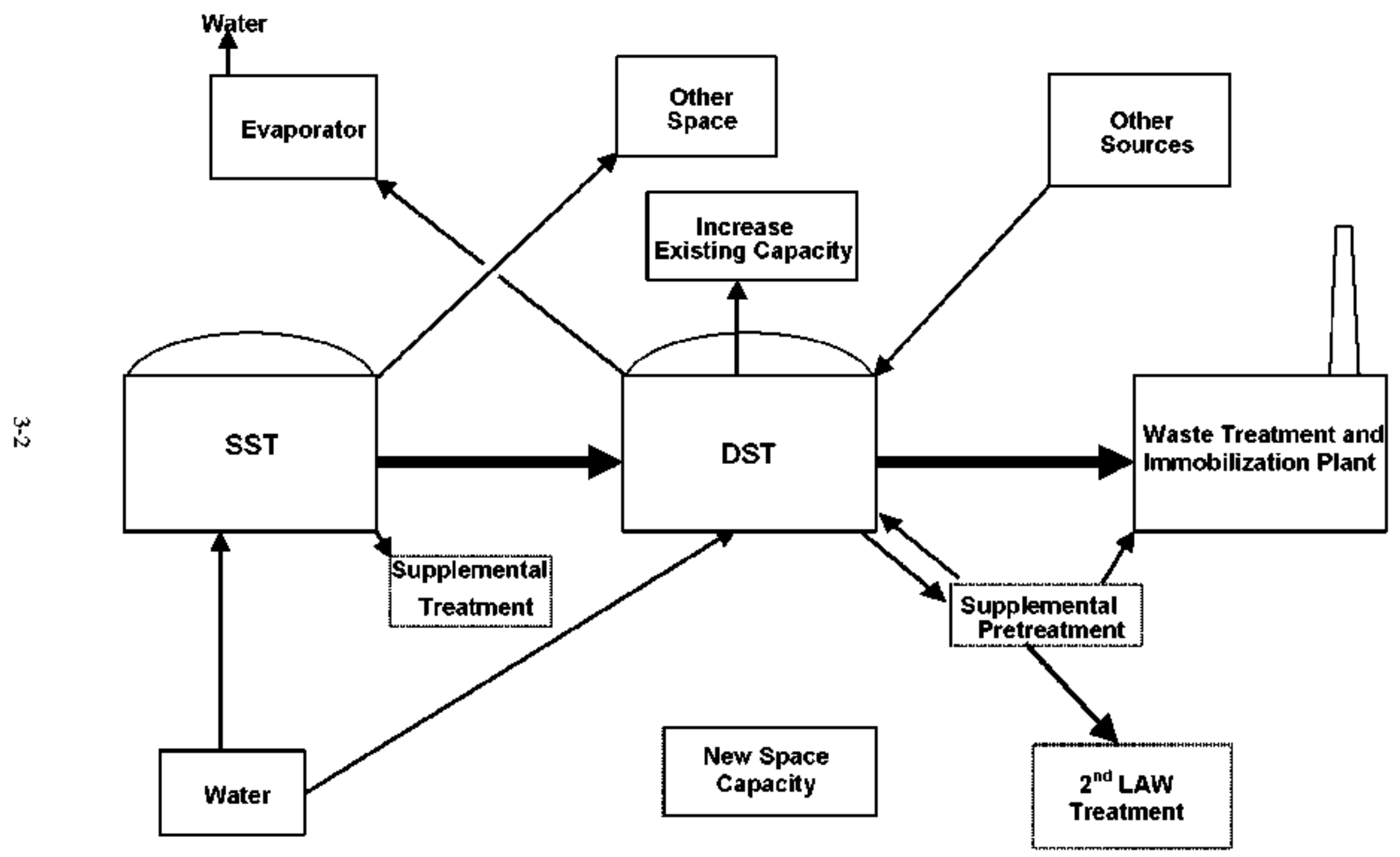




\section{OPTIONS EVALUATED WITH HIGHEST POTENTIAL TO ALLEVIATE 2018-2025 TANK SPACE SHORT AGE}

Thirteen options that encompass the construction of new capacity, modification of eurrent storage practices, and waste treatment alternatives are identified and described in this chapter. These options were selected for evaluation because they exhibited the potential to provide additional storage space for retrieval of high-risk SST waste during 2018-2025.

To permit future evaluation and comparison, information was developed for each option, including storage capacity provided and the approximate cost estimate and schedule to implement. The cost represents an estimate of the activities necessary to incorporate the capacity into the programmatic planning basis and not life-cycle costs. Most are one-time activities which, when implemented, become part of the baseline. Closure costs were specifically excluded for this comparison because of the uncertainty in closure criteria. Closure costs apply across all options, and will vary depending on the option. As such, closure costs should be considered but may not always be a key discriminator between options.

The construction of new DSTs ("new tank" option) is the benchmark for comparison of options. The design has been through extensive review. A detailed cost estimate and schedule were developed in the early 1990 s and serve as the basis of the estimate for this report.

A qualitative discussion of other considerations is summarized for each option. Technical feasibility, environmental risk, health and safety risk, maintainability and operability, environmental regulatory impacts, and authorization basis impacts were evaluated. Table 4-1 contains criteria used for the qualitative evaluation.

Table 4-2 is a summary of the options showing the estimated gain in DST storage capacity, the cost, and the schedule to implement each option. For this study, the options have been considered independently. Because of the potential overlap between some options, the tank capacities identified in Table 4-2 are not additive. Also, some of the options will permit optimization of WTP operations, which could offset some of the cost of the proposed option.

\subsection{MIX/BLEND FACILITY}

\subsubsection{Description}

This option provides additional storage capacity by adding tank space in a new facility that would provide the capability of mixing tank wastes to facilitate certification and to provide optimized waste mixtures to the WTP. This option is different from the construct new DSTs option because the mix blend facility would be designed specifically to blend tank waste to achieve a minimum volume of glass. The HLW feed certification-characterization facility has been proposed and a cost estimate developed. The HLW feed certification-characterization facility contains large tanks (six 500,000-gallon tanks for a total storage capacity of $3 \mathrm{Mgal}$ ) that could be used for mixing/blending and for storage of tank waste. For purposes of this option, the following benefits should be considered. 
Sampling for characterization and certification of HLW is problematic in DSTs. The mix blend facility would be designed to facilitate sampling of the blended tank for characterization and certification of the batch.

Table 4-1. Performance Evaluation Feasibility Criteria

\begin{tabular}{|c|c|c|c|}
\hline Criteria & High Feasibility & Medium Feasibility & Low Feasibility \\
\hline Technical feasibility & $\begin{array}{l}\text { Work performed } \\
\text { previously. } \\
\text { Minimal physical change } \\
\text { to system s/facilities. } \\
\text { Little change to process } \\
\text { documents. }\end{array}$ & $\begin{array}{l}\text { Performed previously } \\
\text { Moderate physical change } \\
\text { to facilities or systems. } \\
\text { Process documents and } \\
\text { procedures require } \\
\text { change. }\end{array}$ & $\begin{array}{l}\text { Never performed before. } \\
\text { Many unknowns. Major } \\
\text { physical changes } \\
\text { Research and development } \\
\text { required. }\end{array}$ \\
\hline Environmental risk. & $\begin{array}{l}\text { No new environmental } \\
\text { risk identified Should } \\
\text { be bounded by existing } \\
\text { permits. }\end{array}$ & $\begin{array}{l}\text { Increased environmental } \\
\text { risk. Minor modifications } \\
\text { to existing permits. }\end{array}$ & $\begin{array}{l}\text { Requires significant } \\
\text { evaluation. } \\
\text { New permits required. }\end{array}$ \\
\hline Health and safety risk & $\begin{array}{l}\text { No new or minimal } \\
\text { exposure to workers } \\
\text { Should be bounded by } \\
\text { current activities. }\end{array}$ & $\begin{array}{l}\text { Possibility of new hazards } \\
\text { that require additional } \\
\text { precautions. }\end{array}$ & $\begin{array}{l}\text { High industrial, radiation, } \\
\text { and construction risk } \\
\text { exposure. Risk within } \\
\text { industry allowable limits, } \\
\text { but requiring special } \\
\text { precautions. }\end{array}$ \\
\hline $\begin{array}{l}\text { Maintainability and } \\
\text { operability }\end{array}$ & $\begin{array}{l}\text { Limited change to } \\
\text { existing operations. } \\
\text { Simple processes. }\end{array}$ & $\begin{array}{l}\text { New operation similar to } \\
\text { existing operation or a } \\
\text { major change to an } \\
\text { existing operation. }\end{array}$ & $\begin{array}{l}\text { New type facility with } \\
\text { complex processes. }\end{array}$ \\
\hline $\begin{array}{l}\text { Environmental regulatory } \\
\text { impacts }\end{array}$ & $\begin{array}{l}\text { Changes to existing } \\
\text { permits are minor. No } \\
\text { impact to HFFACO } \\
\text { milestones or consent } \\
\text { decree milestones. }\end{array}$ & $\begin{array}{l}\text { Major modifications to } \\
\text { existing permits or new } \\
\text { permits. Changes or } \\
\text { additions expected to be } \\
\text { straightforward. }\end{array}$ & $\begin{array}{l}\text { New permits or major } \\
\text { modifications to existing } \\
\text { permits. Significant publio } \\
\text { interest and comment } \\
\text { expected. Request for } \\
\text { variance to regulations } \\
\text { required. }\end{array}$ \\
\hline $\begin{array}{l}\text { Authorization basis } \\
\text { impacts }\end{array}$ & $\begin{array}{l}\text { Unreviewed Safety } \\
\text { Question (USQ) } \\
\text { evaluation indicates no } \\
\text { changes or minor } \\
\text { changes via annual } \\
\text { update. No changes to } \\
\text { the Technical Safety } \\
\text { Requirements. }\end{array}$ & $\begin{array}{l}\text { Updates to the } \\
\text { authorization basis or } \\
\text { controls required. No } \\
\text { significant development } \\
\text { of new safety analyses. }\end{array}$ & $\begin{array}{l}\text { Significant safety analyses } \\
\text { must be prepared to } \\
\text { support an authorization } \\
\text { basis amendment. }\end{array}$ \\
\hline
\end{tabular}


Table 4-2. Summary of Options Most Likely to Provide Additional Capacity in 2018-2025

\begin{tabular}{|c|c|c|c|c|}
\hline Option Title & $\begin{array}{c}\text { Additional } \\
\text { Capacity } \\
\text { (Kgal) }\end{array}$ & $\begin{array}{c}\text { Time to } \\
\text { Implement } \\
\text { (yrs) }\end{array}$ & $\begin{array}{c}\text { Cost } \\
(\$ / g a l)\end{array}$ & $\begin{array}{c}\text { Total Cost } \\
\text { (\$k) }\end{array}$ \\
\hline Construct mix/blend facility & 3,000 & 7 & 122,00 & 370,000 \\
\hline Raise waste levels AN, AW, and SY Farms & $990^{2}$ & 1 & 535 & 5,300 \\
\hline Utilize restricted DST capacity & 733 & 5 & 16.50 & 12,000 \\
\hline Utilize-altemative storage for DST emergency storage & 1,265 & 4 & $\begin{array}{l}18.18- \\
23.71\end{array}$ & $\begin{array}{r}23,000= \\
30,000\end{array}$ \\
\hline Concentrate waste to $1.43 \mathrm{~g} / \mathrm{mL}$ & $3,300^{b}$ & 6 & 6.97 & 23,000 \\
\hline Locally concentrate waste to $1.43 \mathrm{~g} / \mathrm{mL}$ & 3,300 & 5 & 11.82 & 39,000 \\
\hline Concentrate waste to damp saltcake & Up to 9,000 & 5 & 9.89 & 89,000 \\
\hline $\begin{array}{l}\text { Utilize waste retrieval facility surface storage for } \\
\text { retrieved SST waste }\end{array}$ & 1,800 & 7 & 3833 & 69,000 \\
\hline Utilize modular storage for retrieved SST waste & 1,000 & 4 & 2900 & 29,000 \\
\hline Construct new DSTs (per tank) & 1,200 & 7 & 73.00 & 88,000 \\
\hline
\end{tabular}

"Excludes $770 \mathrm{Kgal}$ of currently restricted space that will not be available until tanks AN-102, AN-103, AN-104, AN-105, AN-107, AW-101, and SY-103 are emptied following WTP startup and cperation.

${ }^{b}$ This volume does not include volumes already been accounted for in ORP. 11242 .

Blending Waste can result in fewer canisters of HLW glass. Figure 6-7 in RPP-21216, Single Shell Tank Retrieval Selection and Sequence, demonstrates that complete blending of the HLW waste would result in a total of 10,294 canisters of HLW glass; whereas no blending results in 16,670 canisters (an increase of about $62 \%$ ) of HLW glass. The life-cycle cost for transportation and disposal for a single canister of HLW glass at a national repository is estimated at $\$ 1.2 \mathrm{M}$ (Appendix A). Including the cost of interim onsite storage and approximately 5 years additional operation of the HLW melter facility, the cost of the approximately 6000 additional canisters of HLW glass resulting from not blending tank waste is estimated at $\$ 10 \mathrm{~B}$. While it is clear that completely blending all $\sim 55 \mathrm{Mgal}$ of waste in a single tank is probably not achievable, significant benefit can likely be achieved by selective retrieval of SST waste and providing the ability to receive, store, and blend wastes.

A mix/blend facility could provide an intermediate facility between the tank farms and the WTP. The mix/blend facility would be designed to receive waste from SSTs and DSTs and potentially other facilities (e.g., modular storage facility) as liquids and solids, provide lag storage for waste, and provide tanks for feed blending, homogenization, and sampling for characterization/ certification of the HLW batch.

A mix/blend facility could also provide a platform for limited pretreatment capability and chemical trimming of the waste to meet WTP requirements. One of the constraints on WTP operations is pretreatment of the waste. Designing some pretreatment capabilities into the mix/blend facility may alleviate the loading on the WTP pretreatment system. 
The conceptual mix/blend facility could provide the following functions:

a. Receive waste from

1. DSTs.

2. SSTs.

3. Other facilities (e.g., modular aboveground storage facility).

b. Transfer waste from

1. HLW to WTP.

2. LAWW to DST for staging.

c. Provide capability to homogenize HLW slurry feed.

d. Provide capability to sample homogenized HLW for characterization/certification.

e. Provide capability to stage sufficient blended HLW feed to optimize HLW glass production.

f. Provide capability for additional pretreatment. Possible pretreatment might include the following:

1. Aluminum removal from HLW.

2. Cesium/strontium removal from $L A W$.

3. Chemical trimming to meet WTP WAC.

4. Other processes to be determined.

\subsubsection{Background}

The existing DSTs were not designed to mobilize settled solids (sludge or salt-cake) into the homogeneous slurries for certification prior to transfer to the WTP. The WTP WAC limits solid content, density, viscosity and other parameters in HLW and LAW feeds transferred to the WTP as liquids or slurries. Additionally, feed to the WTP will need to be fully characterized and certified to meet WTP WAC. Tanks containing significant solids content that cannot be homogenized will require a method to obtain representative samples for characterization and certification that the tank meets the WTP WAC. The current method of characterization is to pull core samples from a tank with a solids layer. Even with multiple core samples, there is always a level of uncertainty that samples are representative, so tanks with waste that approaches WTP WAC limits will be at risk for rejection. Wastes containing significant solids content may also present a challenge for transfer to WTP. Although the entire batch may contain the solids content desired, if the batch is not homogenous, the solids content could vary from essentially solids free material at the beginning of the transfer to very high solids content material at the end of the transfer. Designing and controlling transfer systems (pumps and transfer lines) for wastes with significantly different solids content from the beginning to the end of the transfer will likely be difficult and may lead to early failure of equipment. It is also unclear if the limits in the WTP WAC are measured on a continuous basis or are based on an entire batch. If the WTP WAC limits are based on a continuous measurement, then the entire transfer would need to meet the requirements.

It is anticipated that LAW feeds with low solids content can be transferred from DSTs and meet the WTP WAC requirements. Preparing homogenous HLW feeds with up to $200 \mathrm{~g} / \mathrm{L}$ solids 
content for characterization/certification or transfer to WTP will likely be problematic from DSTs. A process test was performed in tank 241-AZ-101 to demonstrate the capability of mixer pumps to mobilize sludge material. While the test demonstrated that the mixer pumps were able to mobilize most of the solids (it was determined that the solids moved around the tank), the test did not demonstrate that operation of the mixer pumps resulted in a homogeneous slurry. To the contrary, the test demonstrated that a significant difference in solid content from the top to the bottom of the tank existed during mixer pump operation (RPP-6548, Test Report, 241-AZ-101 Mixer Pump Test).

Both HLW and LAW feeds will need to be characterized and certified to meet the WTP WAC. This certifieation will require representative sampling using existing grab sampling techniques. Mixing low solids LAW material in the DSTs should be sufficient to allow representative sampling. It will be difficult to demonstrate that sampling of HLW slurries is representative unless the slurries can be demonstrated to be homogeneous. For the purpose of this report "homogeneous" means that the solids content in the slurry at the top of the tank is the same as the solids content in the slurry at the bottom of the tank. Gravity settling of the solid component of the slurry leads to higher solids content in the bottom versus the top in an unmixed tank.

One of the most significant benefits of the mix/blend facility is the ability to blend tank waste to minimize HLW glass. To produce a blended waste to minimize HLW glass, the mix blend facility would need to have simultaneous access to waste from multiple SSTs and DSTs. Transfers could be made between the DSTs and the mix/blend facility using existing transfer lines, but direct transfers to the mix/blend facility from SSTs would be difficult using existing infrastructure. To make the most beneficial use of the mix/blend facility, the capability of introducing waste from multiple SSTs and DSTs would be required.

Conceptually the mix/blend facility would include six 500,000-gallon tanks, which would each have enough capacity to supply three batches of HLW to the WTP. The tanks in the facility would have the capability to receive waste from DSTs and potentially other facilities. The tanks would be used to settle solids and decant supernate. A portion of the supernate (LAW feed) would likely be transferred back to DSTs for staging as LAW, and the solids would be retained to develop a batch of HLW feed. The mix/blend facility could include space to be used for some pretreatment activities.

The tanks and transfer lines in the mix/blend facility would be designed to homogenize, characterize through representative sampling, and transfer slurries. It is anticipated that the tanks would be equipped with multiple mixer pumps and would have conical or dish-shaped bottoms with bottom center discharge. Mixer and transfer pumps would be designed for remote maintenance, and where possible technologies (e.g., Discflo pumps ${ }^{1}$ ) would be used to minimize maintenance requirements.

\footnotetext{
${ }^{1}$ Discflo is a trademark of Discflo Corporation, Santee, California.
} 


\subsubsection{Evaluation of Option}

\subsubsection{Additional Capacity (Gallons)}

This option includes the mix/blend facility. Assuming six tanks of 500,000 gallons each, the additional storage capacity of the $\mathrm{mix} / \mathrm{blend}$ facility is $3000 \mathrm{Kgal}$ of additional storage space.

\subsubsection{Cost}

The following cost estimate has been prepared for the HLW feed certification - characterization facility.

Table 4-3. Cost Estimate for Mix/Blend Facility

\begin{tabular}{|l|c|}
\hline \multicolumn{1}{|c|}{ Activity Description } & Cost (SK) \\
\hline Project management & 43,000 \\
\hline Technology testing & 9,000 \\
\hline Design & 85,000 \\
\hline Procurement and construction & 220,000 \\
\hline Startup and testing & 8,000 \\
\hline Regulatory compliance/safety analysis & 5,000 \\
\hline \multicolumn{1}{|c|}{ Option Total } & $\mathbf{3 7 0 , 0 0 0}$ \\
\hline
\end{tabular}

Based on 3,000,000 gallons of new tank capacity, the cost associated with this option is $\$ 122 /$ gallon.

\subsubsection{Schedule}

Because this is a new project, it would take approximately 7 years to implement. With the current limitations on starting new projects, the earliest the space in this option could be available would be 2021 .

\subsubsection{Feasibility Considerations}

Table 4-4 provides the summary assessment of these considerations.

Table 4-4. Feasibility Considerations for Mix/Blend Facility

\begin{tabular}{|l|c|c|c|}
\hline \multicolumn{1}{|c|}{ Criteria } & High Feasibility & Medium Feasibility & Low Feasibility \\
\hline Technical feasibility & $\mathrm{X}$ & & \\
\hline Environmental risk & $\mathrm{X}$ & & \\
\hline Health and safety risk & $\mathrm{X}$ & & \\
\hline Maintainability and operability & $\mathrm{X}$ & & \\
\hline Environmental regulatory impacts & & $\mathrm{X}$ & \\
\hline Authorization basis impacts & $\mathrm{X}$ & & \\
\hline
\end{tabular}




\section{a. Technical Feasibility}

The mix/blend facility consists of six 500,000 gallon tanks, ancillary pumps and piping systems, and perhaps an area for pretreatment of tank waste. Operations would consist of receiving and transferring tank waste, decanting supemate, and homogenizing slurries. All of the operations listed are technically mature and are currently performed or planned in the tank farms.

\section{b. Environmental Risk}

The mix/blend facility would be designed to meet the requirement of Washington Administrative Code (WAC) 173-303-640 (4)(e)(iii), "Dangerous Waste Regulations," "Tank Systems," that double-walled tanks be designed as an integral structure (i.e., an inner tank completely enveloped within an outer shell) and be provided with a built-in continuous leak detection system. There will be a small increase in risk due to an increased number of transfers, but the increase in efficiency leading to reduced operation of the WTP HLW melters will offset the risk. The overall environmental risk from storage of SST waste in non-compliant storage is reduced by the addition of fully compliant storage space provided by the mix/blend facility

\section{c. Health and Safetr Risk}

Building any new facility involves some risk to construction personnel. Waste transfers from DSTs to the mix/blend facility would be accomplished using existing or new fully compliant transfer lines. Operations in the mix/blend facility would be the same as those currently planned or performed in the tank farms. The mix/blend facility would be designed to protect the worker from radiation and other hazards.

\section{d. Maintainabilitv/Operability}

Although there are new systems involved in a new facility, maintainability and operability would be enhanced in a new mix/blend facility. Pumps and instrumentation systems would be designed to be accessible for maintenance. The same or similar systems that exist in the tank farms would be used in the mix/blend facility. Whereas pumps and instrumentation in the tank farms are exposed to weather (e.g., high and low temperatures, moisture, ultraviolet light), these systems in the mix/blend facility are indoors. Additionally, pumps used in the mix/blend facility would be designed for continuous operation, as compared to similar systems in tank farms which may sit idle for several years between uses.

\section{e. Environmental Requlatory Impacts}

A new mix blend facility would most likely constitute a new treatment, storage, and disposal facility (TSD), and would therefore need to be licensed with the State of Washington Department of Ecology (Ecology). It should be noted that the drivers for the new facility (early retrieval from and mitigation of existing noncompliant storage 
facilities, reduce operating lifetime of WTP, minimize HLW glass volume) should ensure that Ecology would favor this option. There would, however, be more challenges licensing a new facility than would be expected for other options.

\section{f. Authorization Basis Impacts}

A new mix/blend facility is not addressed in the current authorization basis. There would need to be changes to the existing authorization basis to implement this option. Other than potential pretreatment which is not currently defined, activities associated with the mix/blend facility such as tank to tank waste transfers, waste storage and, waste mobilization using mixer pumps are well understood and currently performed in the tank farms. Therefore, the authorization basis impacts were judged to have high feasibility.

\subsection{RAISE ALLOWABLE WASTE LEVEL IN TANKS}

\subsubsection{Description}

This option was originally proposed in Rev, 0 of this document to provide additional storage capacity by increasing the allowable waste levels in the DSTs in AP, AN, AW, and SY Farms. This option has been implemented for DST AP-108, where the level was increased to 454 inches. AP-103 is to have the allowable level raised during 2009, and the remaining AP Farm tanks are scheduled to have their allowable levels raised in 2010 . The current operating capacity for these DSTs used for planning purposes is $1140 \mathrm{Kgal}$ (HNF-EP-1082), which corresponds to an operating level of 416 inches. This option assumes that the DSTs in the nine available tanks in the AN, AW, and SY Farms in addition to the remaining seven tanks in AP Farm are filled to an operating level of 454 inches $(1250 \mathrm{Kgal})$. The nine tanks are AN-101, AN-106, AW-102, $\mathrm{AW}-103, \mathrm{AW}-104, \mathrm{AW}-105, \mathrm{AW}-106, \mathrm{SY}-101$, and $\mathrm{SY}-102$. The remaining tanks in $\mathrm{AN}, \mathrm{AW}$, and SY Farms are restricted from receiving additional waste.

The four DSTs in the AY and AZ Farms are a different design than the remaining 24 DSTs. Tanks in AY and AZ Farms were excluded from this option in Rev. 0 of this report based on the design of the tanks. Tanks AY-101 and AY-102 and AZ-101 and AZ-102 have sidefill lines, which limit operations to a maximum level of 356 inches $(979 \mathrm{Kgal})$. The remaining $24 \mathrm{DSTs}$ are filled from risers in the tops of the tanks. The facility engineer has stated that it may be possible to cap the side penetrations and fill the AY and AZ tanks to a higher level than 356 inches. An evaluation to determine if capping and raising the allowable levels in AY and AZ tanks is feasible and cost effective would need to be completed prior to taking this action.

\subsubsection{Background}

The current operating capacity of DSTs is based on filling the tanks to a level of 416 inches, which provides a margin below the historic safety limit of 422 inches. The 422 -inch limit is based on seismic calculations performed in the $1980 \mathrm{~s}$, and 422 inches was the maximum waste level used in the calculations. The results did not show a "failure or yield" condition. Subsequent analyses (WHC-EP-0504, Soil Structure Interaction Analysis for Hanford Site 241-SY-101) suggest that the fill limit might be raised. The current safety basis for DSTs indicates that tank structural integrity is not challenged due to increased waste levels; therefore, 
structurally based level limits are not required in the authorization basis (RPP-13033, Tank Farms Documented Safety Analysis).

In 1998, because of the waste surface level rise in tank SY -101, the maximum waste level in DSTs was readdressed. An evaluation specific to SY-101, Evaluation of Waste Level Limits in Tank 241-SY-101 (HNF-3555, Evaluation of Waste Level Limits in Tank 241-SY-101) identified that a physical constraint on increasing the DST fill limit is the loss of double containment. The loss of double containment occurs where the annulus tank and the primary tank walls meet at approximately 460 inches. The SY and AP tanks were hydrostatically tested to the 454-inch level prior to use.

For evaluation of this option, a maximum operating level of 454 inches is assumed.

Technical studies will be required to verify the feasibility of increasing the level, including an updated seismic/structural analysis, a review of the tank wall thickness, and a tank-by-tank review of equipment. The effects of changes in flammable gas concentrations caused by a reduction of headspace volume will require evaluation. The final operating level adopted could be higher or lower as a result of these studies.

The Resource Conservation and Recovery Act of 1976 (RCRA) Part B permit allows waste up to 460 inches in AP Farm, 422 inches in AN, AW, and SY Farms, and 370.5 inches in AY and AZ Farms. The Part B permit would need to be revised to raise the allowable levels in $\mathrm{AN}, \mathrm{AW}$, and SY Farms. Several operating and engineering documents would require revision. No capital equipment is required, but some modification to existing instrumentation would be required; i.e, instrumentation may need to be raised.

\subsubsection{Evaluation of Option}

\subsubsection{Additional Capacity (Gallons)}

The current waste volume projections use a tank capacity of $1140 \mathrm{Kgal}$ (416 inches) for each of the 16 tanks located in AN, AW, and SY Farms. This option assumes that the nine tanks in AN, AW, and SY Farms that do not have restrictions on the addition of new waste can be filled to $1250 \mathrm{Kgal}$ (454 inches), thereby allowing an additional $110 \mathrm{Kgal}$ of waste storage per tank. Raising the fill limit for these nine DSTs will create an additional $990 \mathrm{Kgal}$ of storage space. Raising the tank levels in AP Farm to 454 inches allows an additional $110 \mathrm{Kgal}$ of waste storage per tank. Raising the fill limit for the remaining seven tanks in AP Farm will create $770 \mathrm{Kgal}$ of storage space. However, it is important to note that this AP Farm storage space is assumed in ORP-11242 and is already included in the project baseline. The total additional capacity to be gained in the period from 2018 through 2025 from raising the levels in the DSTs is therefore $990 \mathrm{Kgal}$. For tanks AN-102, AN-103, AN-104, AN-105, AN-107, AW-101, and SY-103, the space potentially available by raising the allowable limit in the tanks ( $770 \mathrm{Kgal}$ ) will not be available until the current contents are processed because the tanks are restricted due to classification as flammable gas waste group $\mathrm{A}$ or complex concentrate tanks.

Even though the capacity of the restricted tanks will not be available until the current contents are processed, there may be a benefit to do the structural evaluation, etc., now to allow the tank 
levels to be raised in the future. If these tanks are similar to the other tanks to be evaluated, there may be a reduced cost in doing the evaluations at the same time. Repositioning internal equipment and instrumentation would need to be delayed until the current contents are processed.

\subsubsection{Cost}

The cost estimate for this option is presented in Table 4-5 and is based in large part on the cost estimate for raising the level in AP-103.

Table 4-5. Cost Estimate for Raising Allowable Waste Levels Option

\begin{tabular}{|l|c|}
\hline \multicolumn{1}{|c|}{ Activity Description } & Cost (SK) \\
\hline Conduct flammable gas craluation & 100 \\
\hline Update structural/seismic evaluation & 1,500 \\
\hline Evaluate minor equipment needs & 20 \\
\hline Revise RCRA Part B Permit & 60 \\
\hline Revise operating documents & 120 \\
\hline Leak test and instrument modification & 3,500 \\
\hline \multicolumn{1}{|c|}{ Option Total } & $\mathbf{5 , 3 0 0}$ \\
\hline
\end{tabular}

Based on 990,000 gallons of new tank capacity, the cost associated with this option is $\$ 5.35$ /gallon.

The cost estimate is based on the following assumptions:

a. A total of nine DST tanks will be included in the flammable gas evaluation.

b. Any required unreviewed safety questions (USQ) are screened in the flammable gas and structural seismic evaluations (this is for verification of envelope only and not for final certification).

c. No further USQ resolutions are necessary.

d. No additional flammable gas monitors are required.

e. No major equipment modifications are required.

f. Updates to existing structural and seismic calculations will form the basis for new analysis.

The following potential costs are excluded from the estimate:

a. Waste transfers required to fill the tanks to 454 inches ( 24 transfers $x \$ 130 \mathrm{~K}$ per transfer $=\$ 3,120 \mathrm{~K})$.

b. BDGRE and issue resolution cost.

c. Compatibility assessments $\$ 20 \mathrm{~K}$. 
Waste transfer costs are a routine cost because the tanks can be filled as needed.

\subsubsection{Schedule}

The evaluation of this option and implementation of changes needed to modify equipment in tanks and revise engineering and operations documents would take approximately 1 year to complete. Completion could be accomplished before the 2018-2025 need dates.

\subsubsection{Feasibility Considerations}

Additional considerations for the feasibility of raising the allowable waste levels in DSTs are discussed in the following. Table 4-6 provides the summary assessment of these considerations.

Table 4-6. Feasibility Considerations for Raise Allowable Waste Levels

\begin{tabular}{|l|c|c|c|}
\hline \multicolumn{1}{|c|}{ Criteria } & High Feasibility & Medium Feasibility & Low Feasibility \\
\hline Technical feasibility & & $\mathrm{X}$ & \\
\hline Environmental risk & $\mathrm{X}$ & & \\
\hline Health and safety risk & $\mathrm{X}$ & & \\
\hline Maintainability and operability & $\mathrm{X}$ & & \\
\hline Environmental regulatory impacts & $\mathrm{X}$ & & \\
\hline Authorization basis impacts & $\mathrm{X}$ & & \\
\hline
\end{tabular}

\section{a. Technical Feasibility}

The DST operating capacity limits are below maximum tank capacities. The existing tank structural evaluations for some of the tanks indicate that it is probable that tank waste level limits may be raised. The tanks in AW and AN Farms were not hydrostatically tested to the 454 -inch level during construction. The technical uncertainty associated with this option is the development of a feasible method for testing the welds from the level they were tested at during construction and the 454-inch level.

Existing/new structural analyses for the different DSTs may not support a higher waste level or the structural analysis may not meet current standards. If this documentation must be updated extensively, a significant cost and schedule delay would be incurred. Raising the allowable waste levels would require new flammable gas generation rate and ventilation rate studies. The allowable waste level can be increased provided the structural evaluation and the flammable gas review are favorable.

\section{b. Environmental Risk}

The DSTs meet the requirement of WAC 173-303-640 (4)(e)(iii) that double-walled tanks be designed as an integral structure (i.e., an inner tank completely enveloped within an outer shell) and be provided with a built-in continuous leak detection system. Minimal incremental environmental risk is incurred by operating the DSTs at a higher waste level but below the level of the secondary containment. 


\section{c. Health and Safety Risk}

No additional health and safety risk to the workers or the public are expected from raising the allowable waste level in DSTs.

\section{d. Maintainabilitv/Onerability}

No additional maintenance or operational complexity are required to implement this option other than the one-time costs to reposition some equipment and instrumentation.

\section{e. Environmental Regulatory Impacts}

A minor change to the RCRA Part B permit may be required because the DST headspace has been reduced.

\section{f. Authorization Basis Impacts}

Raising the allowable waste levels would require new flammable gas generation rate and ventilation rate studies. These could possibly result in changes to HNF-SD-WM-TSR-006, Tank Farms Technical Safety Requirements, the Limiting Condition for Operation 3.2.1, "DST Primary Ventilation Systems," surveillance frequency and action statement completion times. The existing waste temperature limits would still apply, and the addition of waste is anticipated to have an insignificant effect on the waste temperature.

\subsection{DECREASE DEDICATED OPERATIONAL SPACE}

\subsubsection{Description}

The option to decrease dedicated operational space was included in Rev. 0 of this document. The proposed changes were implemented.

Based on current plans to retrieve the remaining C Farm SSTs and AX and A Farm SSTs prior to the startup of the WTP, essentially all of the nonemergency DST volume will be filled in the next 10 years. Since the 2001 report, the category "dedicated operational space" was eliminated, and the volume is now included in the normal operational tank volumes. Therefore the tank volumes identified in Rev, 0 for this option are already credited in system planning.

\subsection{USE RESTRICTED TANK CAPACITY}

\subsubsection{Description}

The option to use restricted tank capacity was included in Rev. 0 of this document. The proposed changes with respect to use of restricted tank capacity were implemented to the extent possible, the Watch List was administratively closed, and system planning has changed the DSTs identified as WTP feed source tanks. The available volume identified in Rev. 0 was used, or will soon be used, to retrieve SST waste. 
Based on current plans to retrieve the remaining C Farm SSTs and AX and A Farm SSTs prior to the startup of the WTP, essentially all of the nonemergency nonrestricted DST volume will be filled in the next 10 years. Therefore, the tank volumes identified in Rev. 0 for this option have already been credited in system planning.

The only currently restricted tank for waste feed delivery is AY-102. The currently restricted tanks associated with flammable gas waste group A and complex concentrate waste are AN-102, AN-103, AN-104, AN-105, AN-107, AW-101, and SY-103. The space in restricted tanks is $974 \mathrm{Kgal}$ (HNF-EP-0182). Of this total, $798 \mathrm{Kgal}$ of the available space is in flammable gas waste group A tanks and $176 \mathrm{Kgal}$ is in complex concentrate tanks. Until the flammable gas and complex concentrate issues are mitigated, this space cannot be used.

A possible method of mitigating the flammable gas issue is to install waste mixer pumps in the flammable gas waste group A tanks. The efficacy of this method (mixing) was demonstrated in the early 1990 s on tank SY-101. The current tank farms authorization basis control for flammable gas is based on limiting waste additions to tanks that might otherwise be subject to BDGREs. Preventing a BDGRE using mixer pumps would require a significant change to the current authorization basis philosophy. Installation of mixer pumps in the flammable gas waste group A tanks, to reclaim the $798 \mathrm{Kgal}$ of tank space potentially available, has not been further evaluated in this report.

A possible method of mitigating the complex concentrate issue is the addition of chemicals to the tanks to destroy the chemical complexants present in the waste. Only a minimal amount of tank space could be gained by this operation $(176 \mathrm{Kgal}$ minus the volume of chemicals added to the tanks to destroy the complexants). This option has not been further evaluated in this report.

\subsubsection{Evaluation of Option}

\subsubsection{Additional Capacity (Gallons)}

Three tanks (SY-103 with $424 \mathrm{Kgal}$ of available space, AN-103 with $200 \mathrm{Kgal}$ available space, and $\mathrm{AN}-104$ with $109 \mathrm{Kgal}$ of available space) are candidates for installation of mixer pumps to mitigate flammable gas BDGRE issues. The additional capacity to be gained is $733 \mathrm{Kgal}$. AN-105 and AW-101, which contain a combined $65 \mathrm{Kgal}$ of available space, are not worthwhile candidates for installation of mixer pumps.

\subsubsection{Cost}

The cost estimate for the option of mitigating flammable gas tanks by adding mixer pumps is presented in Table 4-7. 
RPP-7702, Rev. 1

Table 4-7. Cost Estimate for Utilize Restricted Tank Capacity

\begin{tabular}{|c|c|}
\hline Activity Description & $\begin{array}{l}\text { Cost } \\
\text { (\$K) }\end{array}$ \\
\hline Change authorization basis documentation & 5,000 \\
\hline Conduct design & 700 \\
\hline Procure pumps & 4,200 \\
\hline Installation & 1,200 \\
\hline Perform startup and testing and operation & 1,000 \\
\hline Option Total & 12,100 \\
\hline
\end{tabular}

Based on 733,000 gallons of new tank capacity, the cost associated with this option is $\$ 16.50$ gallon.

The cost estimate is based on the following assumptions:

a. One mixer pump is installed in each of three tanks (SY-103, AN-103, and AN-104).

b. Large cost associated with modification of authorization basis from watch list type control to active mixing as control for flammable gas tank.

c. The same mixer design is used in all three tanks.

This is a preliminary cost estimate and is not of budget grade but is for scoping purposes only.

\subsubsection{Schedule}

The evaluation of this option and implementation of authorization basis changes needed to allow use of mixer pumps to mitigate flammable gas would take approximately 5 years to complete.

\subsubsection{Feasibility Considerations}

Additional considerations for the feasibility of use restricted tank capacity are discussed in the following. Table 4-8 provides the summary assessment of these considerations.

Table 4-8. Feasibility Considerations for Utilization of Restricted Tank Capacity

\begin{tabular}{|l|c|c|c|}
\hline Criteria & High Feasibility & Medium Feasibility & Low Feasibility \\
\hline Technical feasibility & $\mathrm{X}$ & & \\
\hline Environmental risk & $\mathrm{X}$ & & \\
\hline Health and safety risk & & $\mathrm{X}$ & \\
\hline Maintainability and operability & & $\mathrm{X}$ & \\
\hline Environmental regulatory impacts & $\mathrm{X}$ & & \\
\hline Authorization basis impacts & \multicolumn{3}{|}{$\mathrm{X}$} \\
\hline
\end{tabular}

\section{a. Technical Feasibility}

The technical feasibility of the use of mixer pumps to mitigate the flammable gas in restricted tanks was demonstrated at Hanford in the mid 1990s in SY-101. Therefore the technical feasibility of this option is judged to be high. 


\section{b. Environmental Risk}

The use of mixer pumps to mitigate flammable gas tanks is judged to result in no significant increase in environmental release over the current practice of passive control because the waste remains in the DST. Additionally, this alternative would result in transfer of waste from non-compliant SSTs into compliant DSTs. This alternative is therefore judged to have high feasibility for environmental risk.

\section{c. Health and Safetv Risk}

The purpose of installation and operation of mixer pumps in the flammable gas group A tanks would be to recover the restricted capacity by adding additional waste to these tanks. The addition of waste to these tanks would result in an increase in the probability that these tanks would retain and episodically release flammable gas. Although the mixer pumps would mitigate the flammable gas, the mitigation would require a new active control as compared to the existing passive control, and therefore the probability of a significant release of flammable gas would be increased over current practice. The health and safety risk is therefore judged to be medium feasibility.

\section{d. Maintainahilitv/Onerability}

This option involves installation of new equipment (mixer pumps) that must be maintained and operated. Compared to the current passive control practice, the maintainability and operability of this option is judged to be moderate feasibility.

\section{e. Environmental Regulatorv Impacts}

Addition of a mixer pump would not result in change to regulatory permit documents or additional environmental releases, and therefore, from the perspective of environmental regulatory impacts, this option is judged to be highly feasible.

\section{f. Authorization Basis Impacts}

Flammable gas retention and periodic release from SY-101 resulted in the U.S. Congress implementing the Flammable-Gas Watch List in the Wyden Amendment. The Flammable-Gas Watch List required Secretary of Energy approval of any waste transfer to a watch-list tank. Although the Watch List has expired, the current controls for flammable gas waste group A tanks are based on the same philosophy that additions of waste to these tanks with a potential to have a BDGRE are prohibited. It is therefore considered to be quite difficult to change the current authorization basis to allow transfers of waste to these tanks, particularly of concentrated waste (desirable for SST retrieval). Although operation of the mixer pump would mitigate the flammable gas retention, it would presumably need to be demonstrated that a mixer pump would not fail or that a failed mixer pump could be replaced prior to the tank retaining and then releasing flammable gas. It is difficult to envision how either of these conditions could be 
adequately demonstrated. The authorization basis impact for this option is therefore judged to be low feasibility.

\subsection{COMBINE AGING WASTE}

\subsubsection{Description}

The option to combine aging waste was included in Rev. 0 of this document. In a modified form, the proposed changes were implemented. Waste in AZ-102 was transferred to other DSTs. The available volume identified in Rev. 0 is currently slated for receipt of SST waste. The total available volume in the AZ tanks is $820 \mathrm{Kgal}$ (HNF-EP-0182).

Based on current plans to retrieve the remaining C Farm SSTs and AX and A Farm SSTs prior to the startup of the WTP, essentially all of the nonemergency nonrestricted DST volume will be filled or unavailable during the next 10 years. Therefore the tank volumes identified in Rev. 0 for this option were already credited in system planning.

\subsection{USE ALTERNATIVE STORAGE FOR EMERGENCY STORAGE}

\subsubsection{Description}

The option to use alternative storage for emergency storage was included in Rev. 0 of this document. The first sub-option listed under this option, combine DST emergency reserve with WTP emergency return reserve, was implemented. The current emergency reserve capacity has been reduced to $1265 \mathrm{Kgal}$ (HNF-EP-0182). The remaining sub-options if implemented would result in a maximum of $1265 \mathrm{Kgal}$ of additional storage volume.

This option considers other emergency storage capacity outside of the DST system. Four options are considered:

a. Utilize one of the four empty grout vaults (218-E16-104 and 218-E16-105).

b. Utilize two of the four empty grout vaults, modified to include primary containment tanks inside the vaults.

c. Utilize double-contained receiver tanks (DCRT).

d. Utilize a large $(\sim 500 \mathrm{Kgal})$ storage tank near the PUREX facility

\section{Grout Vaults without Modification}

Five underground vaults were constructed for disposal of grouted low-level tank waste. One was filled with grouted waste. The remaining four are empty and do not have an identified mission. Each vault has a total capacity of $1600 \mathrm{Kgal}$, with a practical operating capacity of $1400 \mathrm{Kgal}$.

The regulatory strategy for the grout program in the 1990 s was to operate each vault as a surface impoundment and close as a landfill after the grout had solidified. Primary containment was provided by the asphalt liner and concrete vault. Secondary containment was provided by the lined catch basin with a leachate collection sump. 
The U.S. Environmental Protection Agency considers storage of hazardous wastes in a surface impoundment to be disposal. Therefore, only wastes meeting land disposal restrictions (LDR) treatment standards may be stored in an impoundment (Elsevier 1999, Land Disposal Restrictions Compliance Guide). Tank waste does not meet LDR treatment standards for several reasons. Tank waste is classified as corrosive unless treated. In addition, the chromium concentration and the concentrations of several other constituents typically exceed the LDR criteria. Therefore, the vaults could not be operated as surface impoundments for routine tank waste storage.

The grout vaults could be operated as tanks for emergency backup to tank storage. It is recognized that there are significant regulatory challenges to the use of unmodified grout vaults for storage of liquid tank waste. The concrete tank with sprayed asphalt liner (approximately 60 mils thick) could be considered a tank for emergency storage purposes. If the sprayed liner failed, the waste could migrate through the concrete vault, down the drainage net, and along the high-density polyethylene layer located between the concrete and the 1 -m-thick external asphalt barrier down to the lined, gravel-filled catch basin, which provides secondary containment.

The 1-m-thick asphalt barrier surrounding the catch basin and concrete vault was designed to prevent water vapor from migrating from the soil to the grout monolith. It is clear that the asphalt barrier would divert any liquid waste leaking from the vault into the lined catch basin. However, the asphalt barrier would not typically be considered secondary containment. Design aspects that might allow waste to escape the asphalt barrier require evaluation. If the existing design is approved through the permitting process, or if a waiver to design requirements is granted, then credit could be taken for the asphalt barrier as secondary containment.

If credit cannot be taken for the asphalt barrier, then only the gravel-filled, high-density polyethylene-lined catch basin would provide secondary containment. The current structure could be considered double-contained with a capacity of approximately 50,000 gallons.

\section{Grout Vaults with Modification}

If additional containment is necessary, $\operatorname{tank}(\mathrm{s})$ could be constructed inside the vault. In this case, the vault liner and the concrete vault would constitute secondary containment. The existing 60-mil sprayed asphalt liner is fragile, and protecting it from the rigors of construction would be a challenge. It is assumed that installation of a new liner would be required.

The vaults have a rectangular cross section with interior dimensions of 123.5 feet $\mathrm{x} 50.5$ feet and a height of 34 feet. If a rectangular cross section is chosen for an inner tank, then a volume of approximately $1000 \mathrm{Kgal}$ is conceivable. Another concept suggested would be to arrange prefabricated steel tanks inside a vault. One example is a tank used in the petroleum industry, commonly referred to as a Baker ${ }^{2}$ tank. These tanks are $21-\mathrm{Kgal}$ tanks with a rectangular cross section of 8 feet by approximately 37 feet. About 15 of these tanks could be placed in a single vault, for a total capacity of $315 \mathrm{Kgal}$.

\footnotetext{
${ }^{2}$ Baker is a registered trademark of BakerCorp, Seal Beach, California.
} 


\section{Double-Contained Receiver Tanks}

The 244-BX, 244-CR, 244-S, and 244-TX DCRTs have been used as lift stations for waste transfers but will not be used during tank retrieval. The 244-U DCRT has not been used and would incur significant effort to commission. The operating capacity is shown in Table 4-7.

\section{Plutonium-Uranium Extraction (PUREX) Storage Tank}

A PUREX storage tank (tank A-201) was identified during preliminary planning discussions for this study. This is a single-wall, aboveground tank located east of the PUREX facility originally used for storing emergency cooling water. The tank is not acceptable for storing tank waste, which requires shielding and double containment. This tank was not evaluated any further.

\section{Summarv of Alternative Storage for Emergencv Reserves}

Table 4-7. Summary of Alternative Storage for Emergency Reserves

\begin{tabular}{|l|l|l|l|}
\hline \multicolumn{1}{|c|}{ Facility Type } & \multicolumn{1}{|c|}{ Facility Name } & \multicolumn{1}{c|}{$\begin{array}{c}\text { Capacity } \\
\text { (Kgal) }\end{array}$} & \multicolumn{1}{|c|}{$\begin{array}{c}\text { Operating Capacity } \\
\text { (Kgal) }\end{array}$} \\
\hline \multirow{2}{*}{ Grout vaults } & $\begin{array}{l}218-\mathrm{E} 16-104, \\
218-\mathrm{E} 16-105\end{array}$ & $\begin{array}{l}1,600 \text { per } \\
\text { vault }\end{array}$ & 1,265 per vault \\
\hline \multirow{2}{*}{ Modified grout vaults } & $218-\mathrm{E} 16-104$, \\
& $218-\mathrm{E} 16-105$ & $\begin{array}{l}1,600 \text { per } \\
\text { vault }\end{array}$ & $\begin{array}{l}700 \text { per vault }(1,265 \text { for } \\
\text { two vaults) }\end{array}$ \\
\hline \multirow{3}{*}{ DCRT } & $244-\mathrm{A}$ & 16.3 & 14.3 \\
\cline { 2 - 4 } & $244-\mathrm{BX}$ & 31.0 & 24.8 \\
\cline { 2 - 4 } & $244-\mathrm{CR}$ & 15.0 & 12.0 \\
\cline { 2 - 4 } & $244-\mathrm{S}$ & 20.3 & 16.2 \\
\cline { 2 - 4 } & $244-\mathrm{TX}$ & 31.0 & 24.8 \\
\cline { 2 - 4 } & $244-\mathrm{U}$ & 31.0 & 24.8 \\
\hline \multirow{2}{*}{ PUREX raw water tank } & & 500 & 500 \\
\hline
\end{tabular}

\subsubsection{Background}

The grout vault sprayed asphalt liners were applied in 1991. The available vaults were hydrotested. Further testing would be required to ensure that the liners still retain their integrity. Vaults 218-E16-104 and 218-E16-105 are the suggested choices. Vault 102 is more complex operationally, and the asphalt liner in vault 103 was patched after the hydrotest (letter 92-AMD-006, "Grout Vault 103 Upper Liner Acceptability").

From the 1950 s through the late 1970 s, several DCRTs were constructed. The purpose of these facilities was to support uranium and fission product recovery from SST waste. Later the DCRTs were used as part of the interim stabilization program for consolidation of SST liquid prior to pumping to DSTs. The 244-A, 244-BX, 244-CR, 244-S, and 244-TX were all used for these purposes. The 244-U DCRT was never activated. 


\subsubsection{Evaluation of Option}

\subsubsection{Additional Capacity (Gallons)}

a. Using one grout vault, as currently configured, for emergency reserve capacity could release $1265 \mathrm{Kgal}$ of reserved space within the DST system.

b. Using two modified grout vaults for emergency reserve capacity could release $1265 \mathrm{Kgal}$ of reserved space within the DST system.

c. Use of DCRTs creates minimal emergency reserve capacity.

This option evaluation is based on utilization of one or two of the existing grout vaults. Both unmodified and modified approaches are presented. Modification consists of removing the vault cover, installation of a new vault liner, installation of storage tank(s), and necessary support systems and equipment. Startup, testing, and tumover would be performed.

\subsubsection{Cost}

The cost estimate for the modified grout vault option is presented in Table 4-8 and is based on the conceptual design report, HNF-1975, Immobilized Low-Activity Waste Interim Storage Facility Project W-465. The costs have been escalated to 2009.

\section{Table 4-8. Cost Estimate for Alternative Storage for Emergency Reserves Option - Grout Vaults with Modification}

\begin{tabular}{|c|c|}
\hline Activity Description & Cost (\$K) \\
\hline Obtain permitting and regulatory documentation & 2,000 \\
\hline Conduct design & 3,000 \\
\hline Perform construction & 6,000 \\
\hline Ferform startup and testing & 1,000 \\
\hline Closure (only needed if vault is used) & 11,000 \\
\hline Option Total & $23,000^{*}$ \\
\hline
\end{tabular}

s: $\$ 12,000 \mathrm{~K}$ if tanks are not used and closure costs are not incurred

Based on 1,265,000 gallons of new tank capacity, the cost associated with this option including closure costs is $\$ 18.18 /$ gallon. If the vaults are not used and the closure costs are not incurred the cost associated with this option is $\$ 9.49$ /gallon.

The cost estimate is based on the following assumptions:

a. One $\sim 700 \mathrm{Kgal}$ steel tank is installed in each of two vaults.

b. A RCRA Part A and Part B Permit, Notice of Construction, and authorization basis revision are required.

c. Design includes preliminary, conceptual, and detailed design activities.

d. Construction includes site work/excavation, vault entry, and installation of primary containment and auxiliaries. 
e. Startup and testing will consist of a Readiness Review, procedure writing, and training.

f. Approximately 2500 linear feet of hose-in-hose transfer lines will be used.

g. No new transfer pumps are required.

h. A new leachate sump pump is required.

i. Capital modifications will not be required.

j. Existing portable exhauster will be used.

k. Existing Infrastructure will be adequate.

1. Decontamination and decommissioning of new tanks will be required.

The estimated spread of costs is as follows:

$\begin{array}{cc}\text { Year } & \text { Annual Total (\$K) } \\ 1 & 1,100 \\ 2 & 6,700 \\ 3 & 3,400 \\ 4 & 600 \\ 5 & 600\end{array}$

This is a preliminary estimate and schedule of expenditures and is not of budget grade but is for scoping purposes only.

The cost estimate for the unmodified grout vault option is presented in Table 4-9 and is based on the modified grout vault estimate.

Table 4-9. Cost Estimate for Alternative Storage for Emergency Reserves Option - Grout Vaults without Modification

\begin{tabular}{|l|c|}
\hline \multicolumn{1}{|c|}{ Activity Description } & Cost (SK) \\
\hline Obtain permitting and regulatory documentation & 4,000 \\
\hline Conduct design & 1,000 \\
\hline Perform construction & 2,000 \\
\hline Perform startup and testing & 1,000 \\
\hline Closure (only needed if vault is used) & 22,000 \\
\hline \multicolumn{1}{|c|}{ Option Total } & $30,000^{*}$ \\
\hline
\end{tabular}

$* \$ 8,000 \mathrm{~K}$ if tank is not used and closure costs are not incurred

Based on 1,265,000 gallons of new tank capacity, the cost associated with this option including closure cost is $\$ 23.72 /$ gallon. If the vaults are not used and the closure costs are not incurred, the cost associated with this option is $\$ 6.32 /$ gallon. 
The cost estimate for the unmodified grout vaults is based on the following assumptions:

a. Cost estimate reductions are associated with the elimination of a new vault liner, storage tanks and associated systems.

b. Changes to the authorization basis resulting from the use of non-compliant storage (RCRA) are assumed to make the cost of modifying the authorization basis higher than would be expected for the RCRA compliant modified grout vault option.

c. Decontamination and decommissioning cost for unmodified grout vault will be double the cost of decontamination and decommissioning for the modified grout vault due to the more complex operation involved and the larger volume of solid waste generated.

\subsubsection{Schedule}

The evaluation of this option and implementation of changes needed to repair/modify equipment, design/construct infrastructure for transfers, revise regulations, and produce operation procedures would take approximately 4 years to complete.

\subsubsection{Feasibility Considerations}

Additional considerations for the feasibility of alternative storage for emergency reserves are discussed in the following. Table 4-10 provides the summary assessment of these considerations.

\section{Table 4-10. Feasibility Considerations for Utilization of Alternative Storage} for Emergency Reserves Option

Unmodified Grout Vaults

\begin{tabular}{|l|c|c|c|}
\hline Criteria & High Feasibility & Medium Feasibility & Low Feasibility \\
\hline Technical feasibility & & $\mathrm{X}$ & \\
\hline Environmental risk & & & $\mathrm{X}$ \\
\hline Health and safety risk & $\mathrm{X}$ & & \\
\hline Maintainability and operability & & & $\mathrm{X}$ \\
\hline Environmental regulatory impacts & & & $\mathrm{X}$ \\
\hline Authorization basis impacts & & $\mathrm{X}$ & \\
\hline
\end{tabular}

Modified Grout Vaults

\begin{tabular}{|l|c|c|c|}
\hline Criteria & High Feasibility & Medium Feasibility & Low Feasibility \\
\hline Technical feasibility & & $\mathrm{X}$ & \\
\hline Environmental risk & $\mathrm{X}$ & & \\
\hline Health and safety risk & $\mathrm{X}$ & & \\
\hline Maintainability and operability & & $\mathrm{X}$ & \\
\hline Environmental regulatory impacts & & $\mathrm{X}$ & \\
\hline Authorization basis impacts & & $\mathrm{X}$ & \\
\hline
\end{tabular}




\section{a. Technical Feasibility}

Use of the grout vaults in their unmodified configuration would have to be evaluated to ensure compatibility between the waste and the liner. The principal long-lead activities would be environmental regulatory permitting and an authorization basis amendment. The main pipelines exist, but several jumpers would need to be fabricated. In addition, emergency procedures would have to be developed.

If tanks are installed within the grout vaults, then additional technical issues must be addressed. These include but are not limited to the following:

1. Excavation of the soil, 1-m-thick asphalt barrier, concrete topping, and pre-stressed concrete cover panels.

2. Construction of a new vault liner.

3. Design, fabrication, and installation of steel tank(s).

4. Replacement of cover panels and overburden.

\section{b. Environmental Risk}

Presently, $1265 \mathrm{Kgal}$ of DST capacity is reserved in the event a DST fails or the WTP has an emergency. Designating one or more grout vaults as emergency reserve capacity would provide the opportunity for retrieval of $1265 \mathrm{Kgal}$ of SST waste in addition to that currently planned prior to 2018 . The designation of the grout vaults for emergency reserve capacity would extend from 2018, when DST capacity is fully utilized, until WTP operations free up DST space (approximately 2025). Therefore, the grout vaults would serve as an emergency reserve for a period of approximately 7 years. Environmental risk for the unmodified option is significantly greater based on possible failure of the 60 -mil sprayed asphalt liner, and therefore obtaining approval to use an unmodified grout for receipt of tank waste is judged to be highly unlikely. Therefore, the environmental risk category for the unmodified grout vault is assigned to the low feasibility category. Because the modified grout vault includes installation of RCRA compliant storage tanks, the environmental risk for the modified grout vault is assigned to the high feasibility category.

\section{c. Health and Safetv Risk}

Minimal additional health and safety risk to the workers or the public are expected by use of alternative storage for emergency reserves. If the modified grout vault option is chosen, a worker confined space hazard must be addressed during modification activities.

\section{d. Maintainabilitv/Operability}

As the grout vaults are not currently in use, operating the vaults as an emergency backup waste storage facility would result in increased maintenance and operations expense for 
the period of use. If the grout vaults are required for waste storage, then closure costs would be incurred. For the purpose of this report, it is assumed that the emergency backup waste storage will remain in the DSTs until 2018 and would revert back to DSTs in 2025. If the need for emergency waste storage did not occur in the critical 7-year time period (2018-2025), there would be no incremental closure costs for the vaults, Reliability and maintainability of the unmodified option is assumed to be somewhat lower based on possible failure of the 60-mil sprayed asphalt liner.

\section{e. Environmental Regulatory Impacts}

A significant activity required for the use of alternative storage for emergency reserves is the environmental regulatory permitting. Environmental regulatory impacts for the unmodified option are greater because of the difficulty in demonstrating a generally acceptable level of secondary containment, which lowers the feasibility of this option.

\section{f. Authorization Basis Impacts}

The grout vaults are currently inactive facilities. Utilizing the grout vaults for waste storage would require a review of the safety analysis for the vaults, WHC-SD-WM-SSP-005, Grout Facilities Standby Plan, and a revision to the authorization basis (RPP-13033) to return the facilities to operational status. This would include facility design and operations descriptions of the alternative storage facilities and associated hazard and accident analyses.

\subsection{CONCENTRATE WASTE}

\subsubsection{Description}

The option of concentrate waste was included in Rev. 0 of this document. Continued operation of the 242-A Evaporator concentrating waste up to a density limit of approximately $1.43 \mathrm{~g} / \mathrm{mL}$, based on the individual tank, is currently planned. Operation of the 242-A Evaporator is included in system planning (ORP-11242). The volume gained through planned 242-A Evaporator campaigns with waste concentrated up to a density of $1.43 \mathrm{~g} / \mathrm{mL}$ does not resolve the shortfall in DST space between 2018 and 2025. The concentrate waste option described in Rev. 0 is retained in this revision and new sub-options are proposed.

One alternative for concentrating waste is to use a mobile skid-mounted system to locally concentrate the waste up to the new density limit. In this new sub-option, a skid-mounted wiped film evaporator is placed near the DST to be evaporated. Liquid is pumped from the tank to the evaporator. The concentrated liquid is returned to the DST, and the overheads are condensed and transferred to the Liquid Effluent Treatment Facility for treatment and disposal. As an alternative technology to the wiped film evaporator, warm dry air could be introduced into the waste via an air sparge to produce small bubbles. As the air bubbles rise through the liquid waste, the air will remove water from the supernatant liquid. Based on the $1.43 \mathrm{~g} / \mathrm{mL}$ density limit, either of these technologies could potentially be used to supplement 242-A Evaporator operations, and would in principle have the same result in terms of volume gained. As with operation of the 242-A Evaporator, concentration of DST waste up to a density of $1.43 \mathrm{~g} / \mathrm{mL}$ is 
included in system planning. Local concentration of DST waste to a density of $1.43 \mathrm{~g} / \mathrm{mL}$ does not resolve the shortfall in DST space between 2018 and 2025.

Another alternative is proposed that removes as much water as practical from DST waste. Single-shell tanks have been stabilized by removing as much liquid as practical leaving only salt or sludge cake with very little free liquid. To remove liquid from the DST waste, BDGREs would need to be addressed. In the early $1990 \mathrm{~s}$, episodic hydrogen gas release events occurred in some DSTs. Tank SY-101 was the most noteworthy of these tanks. Hydrogen is generated in DST waste via radiolysis. In tank SY-101, the hydrogen was trapped in a solids layer at the bottom of the tank. Over time the hydrogen would build up until a sufficiently large accumulation of gas would cause a portion of the solid sludge at the bottom of the tank to become buoyant, rise to the top of the tank, and result in a large release of hydrogen gas. The hydrogen gas releases were large enough that for a period of time the gas in the headspace of the tank exceeded the lower flammability limit.

None of the SSTs are subject to BDGRE behavior, although SST waste may generate and retain radiolytic gas. Therefore, it is assumed that once most of the free liquid is removed from a DST, leaving only the damp saltcake or sludge, a DST would no longer be subject to a BDGRE. To remove liquid from a tank containing saltcake, most of the supernatant liquid could be transferred from the target tank. The remaining liquid and salteake could then be dried to damp salteake using the same techniques used for stabilization of SSTs. More saltcake could then be incrementally added by drying additional supernatant liquid to saltcake using a local evaporator until the desired level of solids in the tank is reached.

Based on a NaOH/NaNO$/ 3$ solubility of $82 \mathrm{~g} / 100 \mathrm{~g}$ of water, about $45 \%$ of the weight of saturated liquid tank waste is $\mathrm{NaOH} / \mathrm{NaNO}_{3}$. At a specific gravity of $1,43,1 \mathrm{~L}$ of saturated waste contains $644 \mathrm{~g} \mathrm{NaOH} / \mathrm{NaNO}_{3}$. Based on the stabilized SSTs, "dry" solids have a bulk density of $1.7 \mathrm{~g} / \mathrm{mL}$ and are approximately $33 \mathrm{wt} \%$ water. Drying tank waste from a specific gravity of $1.43 \mathrm{~g} / \mathrm{mL}$ to the same bulk density as waste in the stabilized SSTs would result in an approximate $50 \%$ waste volume reduction. The new concentration sub-options will follow discussion of the original concentration option.

A concentration limit is established for DSTs to prevent the accumulation and release of flammable gas. The current operating practice is to operate the 242-A Evaporator with a margin below the approved concentration limit to ensure that the limit is not exceeded. If the limit were raised, further concentration of the waste would be possible. There are two phases to this option. The first concentrates waste to the current limit $(1.43 \mathrm{~g} / \mathrm{mL}$; the second establishes a new limit and concentrates the waste to that limit.

\subsubsection{2-A Evaporator Background}

The 242-A Evaporator is used to reduce waste volume by removing water from tank waste. Concentration of the waste is limited to a density of less than $1.43 \mathrm{~g} / \mathrm{mL}$. Tanks AN-102, AN-103, AN-104, AN-105, AN-107, AP-108, AW-101, and SY-103 currently contain wastes that exceed a density of $1.43 \mathrm{~g} / \mathrm{mL}$. Tanks AN-103, AN-104, AN-105, AW-101, and SY-103 are restricted flammable gas waste Group A tanks. 
RPP-7702, Rev. 1

\subsubsection{Evaluation of Option}

\subsubsection{Additional Capacity (Gallons)}

ORP-11242 indicates that fifteen 242-A Evaporator campaigns are planned between 2009 and 2018. Figure 5-8 of ORP-11242 shows that approximately $14 \mathrm{Mgal}$ of waste are scheduled to be processed in the evaporator, reducing the waste volume by approximately $9 \mathrm{Mgal}$. System planning currently includes operation of the 242-A Evaporator to concentrate DST waste to a density of approximately $1.43 \mathrm{~g} / \mathrm{mL}$ or to meet other system objectives. The reduction in waste volume gained from the planned evaporator campaigns does not resolve the DST space shortfall between 2018 and 2025 because ORP-11242 accounts for the reduced volume. It is important to note that if planned evaporator campaigns do not occur, all of the available DST space will be filled prior to 2018, and planned SST retrievals will need to be canceled.

Based on an evaluation of the projected tank volumes and waste concentrations in 2018, DST waste volume could be reduced by approximately $5 \mathrm{Mgal}$ over the current planning basis. In 2018, 11 DSTs (tanks AN-101, AP-101, AP-103, AP-104, AP-106, AP-107, AP-108, AW-103, AY-101, AY-102, and AZ-101) are projected to contain staged waste for WTP. Staged waste is projected to contain a balance of LAW and HLW feeds in correct ratios for WTP. Staged waste is also projected to contain an appropriate concentration of sodium and other constituents in accordance with 24590-WTP-ICD-MG-01-019, ICD-19-Interface Control Document for Waste Feed. Addition of either dilute or concentrated waste to staged waste is undesirable because the addition could result in an incorrect ratio of LAW to HLW, inappropriate concentration of waste constituents, and if the addition occurred after certification sampling, the need to recertify the staged waste tank. In addition to the 11 DSTs containing staged waste for WTP, eight DSTs (tanks AN-102, AN-103, AN-104, AN-105, AN-107, AW-101, AW-104, and SY-103) are projected to contain waste that cannot be concentrated due to waste restrictions such as flammable gas waste group A designation.

The remaining nine DSTs (tanks AN-106, AP-102, AP-105, AW-102, AW-105, AW-106, AZ-102, SY-101, and SY-102) contain supernatant liquid that if concentrated to a density of $1.43 \mathrm{~g} / \mathrm{mL}$, would result in the waste volume being reduced by approximately $3.3 \mathrm{Mgal}$. For a variety of reasons, it would be logistically difficult to concentrate all of the waste to the maximum extent practical. As an example, tanks SY-101 and SY-102 have projected available volume reductions of 604 , and $344 \mathrm{Kgal}$, respectively. To reduce the SY Farm waste volume by the available $948 \mathrm{Kgal}$ using the 242 -A evaporator, the supernatant from SY-101 and SY-102 would need to be transferred cross-site from the 200 West Area to the 200 East Area. A cross-site receiver tank would need to be identified.

The current cross-site receiver tanks are located in AN Farm. In 2018, of the seven available tanks in 200 East Area, tank AW-105 is projected to have the largest projected available volume. In 2018, tank AW-105 is projected to contain $907 \mathrm{Kgal}$ of waste, leaving approximately $253 \mathrm{Kgal}$ in available volume. The total volume to be received from SY Farm to be concentrated is estimated at $1.3 \mathrm{Mgal}$, and therefore approximately five cross-site transfers would be needed. After the cross-site transfer, the supernatant liquid from SY Farm would be transferred from $\mathrm{AW}-105$ to AW-102 for processing through the 242-A Evaporator, and the concentrated waste 
would be transferred to a slurry receiver tank. In 2018, tank AW-102 is projected to contain $1125 \mathrm{Kgal}$ of waste and have an available volume of only $35 \mathrm{Kgal}$. None of the available tanks has been identified as a slurry receiver, and, further, with 19 of the tanks restricted from receipt of new waste, it would likely be logistically difficult to find a slurry receiver tank with sufficient available volume.

It may be possible to make cross-site transfers earlier than 2018 into available 200 East Area tank space. Utilization of 200 East Area tank volume for storage of waste from SY Farm would likely result in the need to change 200 East Area SST retrievals because the available space in 200 East Area DSTs is projected to be filled with waste from A, AX, and C SST farms waste. With changes to the current planning basis and some difficulty (cross-site transfers, identification of a slurry receiver tank, etc.), the projected waste volume could be reduced via concentration in the 242-A Evaporator by up to approximately $3.3 \mathrm{Mgal}$ over the system plan (ORP-11242) planning basis.

\subsubsection{Cost}

The cost estimate for concentration of waste to the $1.43 \mathrm{~g} / \mathrm{mL}$ density limit is presented in Table 4-11,

Table 4-11. Cost Estimate for Concentrate Waste Option

\begin{tabular}{|c|c|}
\hline Activity Description & $\begin{array}{l}\text { Cost } \\
\text { (SK) }\end{array}$ \\
\hline Sample and analyze tanks & 9,200 \\
\hline Perform compatibility assessments & 600 \\
\hline Revise procedures & 200 \\
\hline Cross-site transfers & 3,000 \\
\hline Perform transfers to AW- 102 & 2,400 \\
\hline Perform evaporator campaigns above existing baseline & 5,800 \\
\hline Perform transfers from AW-106 to DSTs & 1,800 \\
\hline Option Total & 23,000 \\
\hline
\end{tabular}

Based on the $3.3 \mathrm{Mgal}$ of DST space discussed in Section 4.7.3.1, the cost of waste concentration in the 242-A Evaporator is \$6.97/gal.

The cost estimate is based on the following assumptions:

a. Waste is concentrated to a density of $1.43 \mathrm{~g} / \mathrm{mL}$.

b. Current evaporator operating costs are prorated by processed waste volume.

c. Waste from nine tanks will be processed in twelve evaporator campaigns.

d. Eight grab samples are collected and analyzed per evaporator waste acceptance criteria at $\$ 600 \mathrm{~K}$ each.

e. 28 compatibility assessments are performed at $\$ 20 \mathrm{~K}$ each. 
f. 16 transfers to the evaporator feed tank and 12 transfers from evaporator receiver tank are performed at $\$ 150 \mathrm{~K}$ each.

A preliminary schedule of expenditures for each additional evaporator campaign follows:

a. Perform all activities for single feed tank campaigns in less than 1 year each, $\$ 1500 \mathrm{~K}$,

b. Perform all activities for two feed tanks per campaign in less than 1 year each, $\$ 2200 \mathrm{~K}$.

The following potential costs are excluded from the estimate: evaporator upgrades and maintenance.

\subsubsection{Schedule}

The schedule is based on one additional evaporator campaign per year. The review and complete implementation of this option would take approximately 6 years. The schedule could be compressed to 3 years by running two additional campaigns per year instead of one.

\subsubsection{Feasibility Considerations}

Additional considerations for the feasibility of concentration of the waste in DSTs are discussed below. Table $4-12$ provides the summary assessment of these considerations based on concentrating waste up to the $1.43 \mathrm{~g} / \mathrm{mL}$ density limit.

Table 4-12. Feasibility Considerations for Additional 242-A Evaporator Campaigns

\section{Concentrate Waste Option}

\begin{tabular}{|l|c|c|c|}
\hline Criteria & High Feasibility & Medium Feasibility & Low Feasibility \\
\hline Technical feasibility & $\mathrm{X}$ & & \\
\hline Environmental risk & $\mathrm{X}$ & & \\
\hline Health and safety risk & $\mathrm{X}$ & & \\
\hline Maintainability and operability & & & $\mathrm{X}$ \\
\hline Environmental regulatory impacts & $\mathrm{X}$ & & \\
\hline Authorization basis impacts & $\mathrm{X}$ & & \\
\hline
\end{tabular}

\section{a. Technical Feasibility}

No technical feasibility issues are identified for the concentration of DST waste to a density of $1.43 \mathrm{~g} / \mathrm{mL}$. The activities that are necessary to concentrate the waste are standard operations at the Hanford Site and no new technology would be required.

\section{b. Environmental Risk}

No incremental environmental risk is incurred by concentration of DST waste to $1.43 \mathrm{~g} / \mathrm{mL}$. 


\section{c. Health and Safety Risk}

Concentration of waste to $1.43 \mathrm{~g} / \mathrm{mL}$ has been fully evaluated and does not pose additional worker and safety risks.

\section{d. Maintainabilitv/Onerability}

No maintainability issues are expected by concentration of DST waste. However, as the DST system becomes filled, the ability to stage waste for evaporator campaigns becomes increasingly difficult. Cross-site transfers are needed to process the waste in the SY tanks, keeping the AW-102 feed tank available and having slurry receiver tanks all become more of a challenge as available space in the DST system decreases. ORP-11242 includes 15 evaporator campaigns over the next 10 years, processing an estimated $14 \mathrm{Mgal}$ of waste and reducing waste volume by an estimated $9 \mathrm{Mgal}$. The number of waste transfers (including cross-site transfers) and 242-A Evaporator campaigns would need to be significantly increased over the current baseline to process the additional approximately $7.6 \mathrm{Mgal}$ of waste necessary to reduce the waste volume by $3.3 \mathrm{Mgal}$. Due to the logistical problems that would need to be overcome for the identified waste volume reduction, maintainability/operability for additional evaporator campaigns is judged to be low feasibility.

\section{e. Environmental Regulatory Impacts}

No environmental regulatory issues are incurred by concentration of DST waste to $1.43 \mathrm{~g} / \mathrm{mL}$.

\section{f. Authorization Basis Impacts}

The tank farm authorization basis (RPP-13033) currently allows concentration up to $1.43 \mathrm{~g} / \mathrm{mL}$. No amendment would be required for concentration up to this limit.

\subsubsection{New Concentration Sub-Options Background}

The 242-A Evaporator is used to reduce waste volume by removing water from tank waste up to a concentration limit. As proposed in Rev. 0, concentration of the waste was increased to limit the density to less than $1.43 \mathrm{~g} / \mathrm{mL}$ (HNF-14755, Documented Safety Analysis for the 242-A Evaporator). The first of the new concentration sub-options evaluates using local evaporation to concentrate the waste to the current limits as a supplement to the 242-A Evaporator. As stated in Section 4.7.3.1, concentration of DST waste to a density of $1.43 \mathrm{~g} / \mathrm{mL}$ is included in System Plan 4 (ORP-11242). Local concentration is evaluated as a supplement to use of the 242-A Evaporator.

In this sub-option, a skid-mounted wiped film evaporator is placed near or preferably over a tank riser. Liquid waste is pumped from the tank to the wiped film evaporator, where the liquid waste is concentrated. The concentrated waste is returned to the tank, and the process condensate is condensed and transferred to the Liquid Effluent Treatment Facility for processing and disposal. 
As an alternative to the wiped film evaporator, warm dry air is sparged into the tank. Heated air introduced into the waste is assumed to cool to the waste temperature as it rises to the liquid surface. The supernatant liquid temperature is approximately $32^{\circ} \mathrm{C}\left(90^{\circ} \mathrm{F}\right)$. Assuming that the inlet air is dry and the outlet air is saturated with water vapor at the waste temperature, the outlet air would remove about $31 \mathrm{~g} / \mathrm{kg}$ dry air. The DST ventilation systems are capable of air flow rates of approximately $3000 \mathrm{cfm}$ per farm or about $500 \mathrm{cfm} / \mathrm{tank}$. With a dry air flow rate of $500 \mathrm{cfm}$ and a temperature of $50^{\circ} \mathrm{C}\left(122^{\circ} \mathrm{F}\right)$, the mass flow rate of dry air into the waste would be about $15.5 \mathrm{~kg} / \mathrm{min}$. The water removal rate would be approximately $480 \mathrm{~g} / \mathrm{min}$, or about $0.48 \mathrm{~L} / \mathrm{min}(0.13 \mathrm{gpm})$. With a constant flow of $50{ }^{\circ} \mathrm{C}$ dry air, the drying rate would be about $690 \mathrm{~L} /$ tank/day (180 gallons/tank/day) or $250,000 \mathrm{~L} / \operatorname{tank} /$ year $(66,000$ gallons/tank/year). Based on the flow rates of dry air and the evaporation rates listed above, the tank waste would cool because $840 \mathrm{KJ} / \mathrm{min}$ more heat would be removed from the waste via evaporation than is added by the $50^{\circ} \mathrm{C}$ dry air. The waste would cool until the heat input from the dry air is equal to the heat loss via evaporation. It might be possible to add a heater (or mixer pump) to the tank to keep the waste at the desired temperature. If a heater is not added, the rate of evaporation would be expected to be significantly lower than the values listed above because of the cooling of the waste. Saturated water vapor would increase the likelihood of water vapor condensing on the relatively cool surfaces of the tank dome. An evaluation would be needed to demonstrate that the condensate would not result in increased corrosion in the tank dome. Because tank heating and condensation issues are not resolved, air sparging is only listed here as an alternative to local evaporation and not further developed.

Concentrating DST waste using a local wiped film evaporator or other local drier could potentially be used in two operational modes. The first operational mode for localized concentration would be as a supplement to 242-A Evaporator operation. In the operational mode where localized concentration is used as a supplement to the 242-A Evaporator, the existing limits for solution density would be followed, and the waste would be concentrated up to the existing density limit of $1.43 \mathrm{~g} / \mathrm{mL}$.

\subsubsection{Evaluation of Option}

\subsubsection{Additional Capacity (Gallons)}

Option 4.7B

Because option 4.7B represents concentration of waste to $1.43 \mathrm{~g} / \mathrm{mL}$, the same concentration presented in option 4.7A (Section 4.7.3), the same volume gains would be made as discussed in that option. As identified in Section 4.7 .4 , approximately $3.3 \mathrm{Mgal}$ of tank space may be gained by additional concentration of waste above the fifteen 242-A Evaporator campaigns credited in ORP-11242. As identified in Section 4.7.4, there are significant logistical difficulties (cross-site transfers, staging dilute, and concentrated slurries in DSTs, etc.) associated with operation of the 242-A Evaporator to reduce the waste volume to the maximum available. The logistical difficulties associated with operation of the 242-A Evaporator could be overcome by the use of local evaporation. The additional capacity available through local evaporation to a supernatant density of $1.43 \mathrm{~g} / \mathrm{mL}$ is the $3.3 \mathrm{Mgal}$ identified in Section 4.7.4. 


\section{Option 4.7C}

Drying and consolidating DST waste may be capable of emptying or essentially emptying up to nine of the DSTs (two AN tanks, one tank each in AW and SY, and five AP tanks), and therefore has the potential to produce an additional DST capacity of up to about $9000 \mathrm{Kgal}$.

\subsubsection{Cost}

Option 4.7B

The cost estimate for local concentration of waste to the $1.43 \mathrm{~g} / \mathrm{mL}$ density limit is similar in many respects to the cost for concentration in the 242-A Evaporator, which is included in baseline planning specified in ORP-11242 and is presented in Table 4-13.

Table 4-13. Cost Estimate for Local Concentrate Waste Option

\begin{tabular}{|l|c|}
\hline \multicolumn{1}{|c|}{ Activity Description } & Cost (\$K) \\
\hline Sample and analyze tanks & 9,200 \\
\hline Perform compatibility assessments & 600 \\
\hline Revise procedures & 200 \\
\hline Development of local wiped film evaporator system & 9,000 \\
\hline Procurement of local wiped film evaporator system & 10,000 \\
\hline Operation of local wiped film evaporator system & 10,000 \\
\hline \multicolumn{1}{|c|}{ Option Total } & $\mathbf{3 9 , 0 0 0}$ \\
\hline
\end{tabular}

Based on approximately $3300 \mathrm{Kgal}$ of space made available via concentration, the cost is $\$ 11.82 / \mathrm{gal}$.

The cost estimate is based on the following assumptions:

a. Cost estimate is a single $100 \mathrm{ft}^{2}$ wiped film evaporator.

b. Sufficient funding provided in FY 2009 and 2010 to continue proof of concept.

c. Includes preliminary safety analysis.

d. Includes detailed shielding analysis.

e. Includes final design and procurement of the first wiped film evaporator system.

The following potential costs are excluded from the estimate: Changes to current authorization basis.

\section{Option 4.7C}

The cost estimate for drying and consolidation of waste to "damp saltcake" is presented in Table 4-14. 
RPP-7702, Rev. 1

Table 414. Cost Estimate for Dry and Consolidate Waste Option

\begin{tabular}{|c|c|}
\hline Activity Description & Cost (\$K) \\
\hline Sample and analyze tanks & 9,200 \\
\hline Perform compatibility assessments & 600 \\
\hline Revise procedures & 200 \\
\hline Evaluation of feasibility of dry and consolidate & 5.000 \\
\hline Development of local wiped film evaporator system & 9,000 \\
\hline Procurement of three local wiped film evaporator systems & 30,000 \\
\hline Operation of drying equipment and waste transfers & 35,000 \\
\hline Option Total & 89,000 \\
\hline
\end{tabular}

Based on the $9000 \mathrm{Kgal}$ of space generated, the cost is $\$ 9.88 / \mathrm{gal}$.

The cost estimate is based on the following assumptions

a. The cost estimate for Option 4.7C is based on the same equipment used in Option 4.7B.

b. Cost estimate is for three $100 \mathrm{ft}^{2}$ wiped film evaporator skids.

c. Sufficient funding provided in FY 2009 and 2010 to continue proof of concept.

d. Includes preliminary safety analysis.

e. Includes detailed shielding analysis.

f. Includes final design and procurement of the first wiped film evaporator system.

g. Evaluation of feasibility includes proof of concept (preparation of saltcake, re-dissolution of saltcake, and retrieval of insoluble waste) testing with stimulant, dose rate evaluation, BDGRE evaluation, and others.

\subsubsection{Schedule}

\section{Option 4.7B}

The evaluation and implementation of option $4.7 \mathrm{~B}$ will include the evaluation of the feasibility of using a thin-film evaporator for locally concentrating the waste, environmental impact studies, designing the system, procuring the equipment, performing safety and shielding analyses, producing the operating procedures, and updating any licensing/regulatory requirements including changes to the authorization basis. It will take approximately 5 years to implement this option.

\section{Option $4.7 \mathrm{C}$}

The evaluation and implementation of option $4.7 \mathrm{C}$ is similar to that of option $4.7 \mathrm{~B}$ with the need for additional studies to evaluate producing dry solids, adding dry solids to a tank already containing waste, avoiding BDGRE conditions in the tanks, feasibility of removing the dry solids from the tank, and characterizing the tank to allow feeding waste to the WTP. Since the studies 
could be run in parallel with the studies being performed for option $4.7 \mathrm{~B}$, the time to implement option $4.7 \mathrm{C}$ would be approximately 5 years.

\subsubsection{Feasibility Considerations}

Additional considerations for the feasibility of the new option for concentration of the waste in DSTs are discussed in the following.

\section{Option 4.7B}

Table 4-15 provides the summary assessment of these considerations based on locally concentrating waste up to the $1.43 \mathrm{~g} / \mathrm{mL}$ density limit using a wiped film evaporator.

Table 4-15. Feasibility Considerations for Locally Concentrate Waste Option (Wiped Film Evaporator)

\begin{tabular}{|l|c|c|c|}
\hline Criteria & High Feasibility & Medium Feasibility & Low Feasibility \\
\hline Technical feasibility & & $\mathrm{X}$ & \\
\hline Environmental risk & & $\mathrm{X}$ & \\
\hline Health and safety risk & & $\mathrm{X}$ & \\
\hline Maintainability and operability & & & $\mathrm{X}$ \\
\hline Environmental regulatory impacts & $\mathrm{X}$ & & \\
\hline Authorization basis impacts & & $\mathrm{X}$ & \\
\hline
\end{tabular}

\section{Option 4.7C}

Table 4-16 provides the summary assessment of these considerations based on locally drying and consolidating waste. The feasibility factors shown are for locally concentrating waste using a wiped film evaporator or similar drying equipment. It is assumed that the supernatant liquid is transferred from the target tank to another DST and all pumpable liquid is removed from the existing saltcake via saltwell pumping as was done for SST stabilization. Once the pumpable liquid is removed, additional saltcake is added to the tank by transferring the original supernatant liquid to a wiped film or other dryer system placed above a tank riser. The supernatant liquid is dried to a loose solid ("damp saltcake") and placed in the tank on top of the existing saltcake. Saltcake from other tanks may be added to the target tanks by transferring supernatant liquid or by dissolving the saltcake and transferring the resultant liquid to the dryer for placement of solids in the target tank.

Table 4-16. Feasibility Considerations for Dry and Consolidate Waste Option

\begin{tabular}{|l|c|c|c|}
\hline \multicolumn{1}{|c|}{ Criteria } & High Feasibility & Medium Feasibility & Low Feasibility \\
\hline Technical feasibility & & & $\mathrm{X}$ \\
\hline Environmental risk & & $\mathrm{X}$ & \\
\hline Health and safety risk & & $\mathrm{X}$ & \\
\hline Maintainability and operability & & $\mathrm{X}$ & \\
\hline Environmental regulatory impacts & & $\mathrm{X}$ & \\
\hline Authorization basis impacts & & & \\
\hline
\end{tabular}




\section{a. Technical Feasibility}

Option 4.7B

No technical feasibility issues are identified per se for the concentration of DST waste to a density of $1.43 \mathrm{~g} / \mathrm{mL}$. Although a wiped film evaporator has not been used in the tank farms, wiped film evaporators have been used to concentrate similar solutions on the Hanford Site. The activities that are necessary to concentrate the waste are standard operations at the Hanford Site and no new technology would be required. A demonstration of the wiped film evaporator would be necessary to demonstrate that a skid-mounted unit could be implemented locally to concentrate tank waste. A cost benefit analysis is needed to determine if local concentration of the waste to $1.43 \mathrm{~g} / \mathrm{mL}$ versus concentration of the waste in the 242-A Evaporator should be pursued. Because the wiped film evaporator technology has not been used to concentrate tank waste, the technical feasibility is judged to be moderately feasible.

\section{Option $4.7 \mathrm{C}$}

Significant development activity would be needed to demonstrate that tank waste could be dried and consolidated in DSTs. In principle, SST stabilization has demonstrated that tanks containing saltcake and sludges can be processed to remove free liquid, "dried." It has not been demonstrated that dry or damp saltcake could be added on the top of the existing saltcake. Dryers are currently used or planned for projects on other DOE sites and are used in the commercial nuclear industry for drying ion exchange resins, salt, and other similar solutions. Based on the potential gains in available DST volume that could be realized if the waste could be dried and consolidated, a detailed study to fully explore the technical challenges of drying and consolidation of waste is needed. Technical feasibility is judged to be low.

\section{b. Environmental Risk}

\section{Option 4.7B}

The baseline option for local concentration involves a skid-mounted wiped film evaporator placed above a tank riser and pumping waste. Waste transfers involve risk of a release to the environment. Waste transfers are also required for operation of the 242-A Evaporator. The wiped film evaporator operates with only a thin film of waste material, and therefore the material at risk is very small compared to the volume of waste transferred between tanks to operate the 242-A Evaporator. Due to the small material at risk in the additional transfers, the environmental risk is judged to be moderately feasible.

\section{Option $4.7 \mathrm{C}$}

The environmental risk associated with drying and consolidation of DST waste will be somewhat higher than that of Option 4.7B because the feed from several DSTs will be 
fed to the evaporator and into a single DST. To do this there will be additional connections and transfer piping required compared to Option 4.7B.

\section{c. Health and Safetv Risk}

\section{Option 4.7B}

Local concentration of waste to $1.43 \mathrm{~g} / \mathrm{mL}$ using a wiped film evaporator poses the same health and safety risk as processing tank waste in the 242-A Evaporator. Processing tank waste in the 242-A Evaporator was fully evaluated and does not pose additional worker and safety risks. Therefore, health and safety risk is judged to be moderately feasible.

\section{Option 4.7C}

Drying and consolidation of tank waste may increase the potential that the waste will retain and periodically release flammable gas (internal memorandum 7E310-94-024. "Evaluation of Specific Gravity Versus Gas Retention," and WHC-SD-WM-TI-755, An Analysis of Parameters Describing Gas Retention/Release Behavior in Double-Shell Tank Waste). This sub-option presents a safety concern that requires technical evaluation. It is likely possible to operate a drying and consolidation system in such a way that retention and periodic release of flammable gas is avoided. The SSTs have been stabilized to remove all free liquids from the saltcake without transitioning through waste that retains and periodically releases flammable gas. Initial drying of the DST waste would follow a similar procedure as the procedure established for SST stabilization. Once the existing saltcake is sufficiently dry (damp salt), additional waste would be dried (damp salt) and placed into the tank on top of the existing saltcake. Development work would need to demonstrate that adding additional damp salt to a tank containing damp salteake would not result in conditions that might lead to BDGREs.

\section{d. Maintainabilitv/Operability}

\section{Option 4.7B}

Maintainability and operability criterion is rated as low feasibility because the skidmounted wiped film evaporator is a new activity with new hardware in the tank farms. The technology is fully mature and it is not anticipated that there would be significant issues with the equipment.

\section{Option 4.7C}

Because the equipment used for drying/consolidation of the DST waste is likely exactly the same as that used for local concentration, the maintainability/operability issues are the same for the drying equipment as in option 4.7B. The retrieval of damp salt from a DST will complicate the retrieval of waste as compared to a DST filled with supernatant liquid. The more complex retrieval operations decrease the feasibility of this option. 


\section{e. Environmental Requlatory Impacts}

\section{Option 4.7B}

Because the local concentration is similar to operation of the 242-A Evaporator, no environmental regulatory issues would be incurred by local concentration of DST waste. Environmental regulatory impacts are judged to be highly feasible.

\section{Option 4.7C}

Because the equipment used for drying and consolidation is the same as that used for local concentration, the environmental regulatory impacts are the same as option 4.7B.

\section{f. Authorization Basis Impacts}

\section{Option 4.7B}

The tank farm authorization basis currently allows concentration up to $1.43 \mathrm{~g} / \mathrm{mL}$. No amendment would be required for concentration up to this limit. An amendment would be required for local concentration of tank waste using a wiped film evaporator. The safety analysis for the wiped film evaporator would need to be performed, but based on the small amount of tank waste in the evaporator, it is anticipated that the accidents evaluated for SST retrieval would bound those for local concentration, and therefore local evaporation is judged to be moderately feasible for authorization basis impacts.

\section{Option $4.7 \mathrm{C}$}

The tank farm authorization basis does not currently address drying of DST waste. Activities needed for drying and consolidation of DST waste are similar to SST stabilization and concentration of waste in the 242-A Evaporator. Drying the waste to a damp solid material would likely need to be limited in such a way that friable material is not generated. For the purpose of this report, it is assumed that the wiped film evaporator could be operated to produce damp solids. Before this option could be implemented, the wiped film evaporator and control system would need to be demonstrated to be capable of producing damp solids rather than friable powder.

\subsection{UTILIZE DOUBLE-CONTAINED SURFACE STORAGE}

\subsubsection{Description}

Alternatives to the construction of new DSTs have been proposed as potential methods for increasing waste storage capacity. Three alternatives for double-contained surface storage evaluated in this option are as follows:

a. Use a compliant bladder in a lined basin similar to Liquid Effluent Retention Facility for interim storage.

b. Expand capacity of planned waste retrieval facilities. 
c. Use of small modular tanks for storage.

\subsubsection{Background}

This option presents three alternatives to traditional underground storage tanks for increasing waste storage capacity. If the waste is retrieved as a liquid, storage in large vessels is appropriate because fewer vessels would be needed. If the waste is retrieved as a solid or retrieved as a liquid and dried to a solid, smaller vessels could be used because emptying small vessels of solids would be feasible and fewer vessels would be needed.

\section{Option 4.8A - Compliant Bladder in a Lined Basin}

This alternative would store tank waste in a regulatory compliant bladder within a lined open-air basin with leak detection. A bladder would be installed inside a Liquid Effluent Retention Facility style basin and would be the primary containment. The secondary containment would be the lined basin. This system would require a feed with low radioactive content to minimize shielding requirements and radiation damage to the bladder. To reduce radioactive content, the SST waste would have to be treated to remove cesium and solids from the waste. The solids have to be removed because it is not possible to remove solids from a bladder and the cesium has to be removed to reduce the radiation effects on the bladder material. For estimation purposes the Interim Pretreatment System costs for removing cesium and solids are appropriate. The Interim Pretreatment System capital costs are approximately $\$ 100,000,000$ for a 5 -gpm system.

\section{Option 4.8B - Waste Retrieval Facilities}

Two waste retrieval facilities will be constructed to support retrieval of SSTs. Waste retrieval facilities, which are similar in function to the existing DCRTs, are planned to be operational near B Farm and T Farm. These facilities with a planned total capacity of $1800 \mathrm{Kgal}$ could be used to store tank waste. Expanding the capacity of the waste retrieval facilities tanks is feasible at this time since their design has not started.

Presently, the design concept is assumed to include six small 150-Kgal tanks constructed in a concrete vault for each facility. The two planned waste retrieval facilities have a total of 12 small tanks. The mission of the tanks is staging retrieved SST waste prior to sending the waste to DSTs. There are a number of options for expanding the waste retrieval facilities capacity including increasing the size of the planned tanks from $150 \mathrm{Kgal}$ to $300 \mathrm{Kgal}$ or adding additional $150-\mathrm{Kgal}$ tanks. Implementation of this option may also require acceleration of the project schedule so that the tank volume would be available when required.

\section{Option 4.8C - Small Modular Tanks for Storage}

The modular storage facility would consist of a concrete pad at grade or an open concrete vault below grade. Concrete culverts would be close packed on the pad or in the vault. Each concrete culvert would contain one $300 \mathrm{ft}^{3}$ capacity tank of waste. The single-wall tank would provide primary containment, and each culvert would be lined with steel to provide secondary containment. The culverts would be fitted with leak detection. The waste from SSTs would be 
retrieved into the $300-\mathrm{ft}^{3}$ tanks transported by truck to the SST farm in a cask. The tank would remain in the cask, and the cask would remain on the trailer during loading with tank waste. When the tank is full, the cask is closed and transported to the modular storage facility. When the cask arrives at the modular storage facility, the tank is removed from the cask, and placed into a culvert for storage. A new tank is placed in the cask and the cask is returned to the SST farm where retrieval continues. To maximize the storage capacity of the modular storage facility, dry retrieval (or possibly wet retrieval and waste drying) would be preferred.

Each modular storage facility would be designed to hold approximately five hundred $300-\mathrm{ft}^{3}$ tanks for a storage capacity of $1000 \mathrm{Kgal}$. The facility would store the waste in compliant storage. The $300-\mathrm{ft}^{3}$ tanks could then be selectively retrieved and optimally blended (DST or mix blend facility) to minimize WTP HLW glass production. As more storage capacity is needed, additional modular storage facilities could be constructed. The simplicity of the storage facility should minimize construction time.

To feed the waste from the modular storage facility to the WTP for processing into glass, the tank is removed from the culvert and placed in a cask at the modular storage facility and transferred to a facility where the waste is transferred into DSTs or into a mix/blend facility. If the tank waste is stored dry, the waste would be dissolved (if dry saltcake) or water would be added and a slurry made (if dry sludge). After re-liquefaction, the waste is transferred into a DST or preferably into a mix/blend facility for preparation of WTP feed.

\subsubsection{Evaluation of Option}

\subsubsection{Additional Capacity (Gallons)}

\section{Option 4.8A - Compliant Bladder in a Lined Basin}

Each Liquid Effluent Retention Facility-style basin with a compliant bladder would add $1000 \mathrm{Kgal}$ of waste capacity beyond that available in the DST system.

\section{Option 4.8B - Waste Retrieval Facilities}

If the waste retrieval facilities design was changed so the $150 \mathrm{Kgal}$ tanks were increased in capacity to $300 \mathrm{Kgal}$ for each of the two facilities, $1800 \mathrm{Kgal}$ of waste storage capacity would be created beyond that available in the DST system $(150 \mathrm{Kgal} \times 6 \times 2=1800 \mathrm{Kgal})$.

\section{Option 4.8C - Small Modular Tanks for Storage}

Assuming a $300-\mathrm{ft}^{3}$ modular storage tank is selected, (there is an existing cask designed for a $300-\mathrm{ft}^{3}$ tank) each tank would contain approximately 2200 gallons. A facility designed to contain 500 of these tanks would have storage capacity of $1100 \mathrm{Kgal}$. The existing modular storage tanks are approximately $6 \mathrm{ft}$ diameter and $11 \mathrm{ft}$ tall. The concrete culverts are assumed to have an outside diameter of approximately $8 \mathrm{ft}$. The 500 concrete culverts in an array of $12 \times 42$ 
would occupy a space of $96 \mathrm{ft} \times 336 \mathrm{ft}$. A Butler $\mathbb{R}^{3}$ or equivalent building designed to house the $12 \times 42$ array would then measure approximately $120 \mathrm{ft}$ by $375 \mathrm{ft}$.

\subsubsection{Cost}

\section{Option 4.8A-Compliant Bladder in a Lined Basin}

Installation of a double-containment surface storage basin and modification to an associated waste retrieval facility were costed. A double-containment surface storage basin will be designed, constructed, tested, and turned over to tank farm operations for beneficial use. The double-containment surface storage will consist of a bladder-type tank located inside a lined earthen basin. The configuration of the basin is similar to the basin that forms part of the existing Liquid Effluent Retention Facility located in the 200 East Area. The storage capacity and size of the bladder tank will be $1 \mathrm{Mgal}$. To utilize a bladder-type tank within an earthen basin for waste storage, cesium and solids must be removed from the waste. The modifications to the waste retrieving facilities will consist of expanding the size of the vault to enable the installation of a process line in each facility that will remove the cesium and solids. The new process equipment will need to be shielded because of high radiation levels and operated remotely. The cost for the Interim Pretreatment System to remove cesium and solids at $5 \mathrm{gpm}$ is approximately $\$ 100,000,000$.

The cost estimate for this option is presented in Table 4-17 and is based on process system cost based on interviews with subject matter experts.

Table 4-17. Cost Estimate for Option 4.8A Compliant Bladder in a Lined Basin

\begin{tabular}{|l|r|}
\hline \multicolumn{1}{|c|}{ Activity Description } & $\begin{array}{r}\text { Cost } \\
\text { (\$K) }\end{array}$ \\
\hline Obtain permitting and regulatory approval & 1,200 \\
\hline Prepare bladder/basin design & 900 \\
\hline Perform bladder/basin procurement and construction & 2,400 \\
\hline 5 gpm system for removing solids and cesium & 100,000 \\
\hline $\begin{array}{l}\text { Perform design, procurement, installation, and testing of waste } \\
\text { retrieval facilities modifications * }\end{array}$ & 5,000 \\
\hline Conduct startup and testing & 1,200 \\
\hline \multicolumn{1}{|c|}{ Option Total } & $\mathbf{1 1 1 , 0 0 0}$ \\
\hline
\end{tabular}

"The costs for this activity reflect a delta or "additional" cost for only the expanded scope. The expanded scope includes specifying two new separation process systems and modifying the facility to accept and operate these systems. The costs for the cesium and liquids removal process equipment are included in the cost estimate.

Based on the estimated $1000 \mathrm{Kgal}$ in Section 4.8.3.1, the cost is $\$ 111 / \mathrm{gal}$.

The cost estimate is based on the following assumptions:

a. A single bladder/basin will be located adjacent to a waste retrieval facility.

\footnotetext{
${ }^{3}$ Butler(is is a registered trademark of Butler Manufacturing, Kansas City, Missouri.
} 
b. The scope of this option will become part of the original design requirements document for the waste retrieval facility and will result in minimal cost increase to the project.

c. The project is of medium complexity based on using standard technologies for the bladder/basin, ion exchange, and filtration systems in a radioactive/hazardous environment.

\section{Option 4.8B - Waste Retrieval Facilities}

The baseline cost of $\$ 127,400 \mathrm{~K}$ for a six-tank waste retrieval facility would need to be accelerated by 3 to 7 years to support this option. The waste retrieval facility would need to be completed prior to the need date between 2018 and 2025 to alleviate the DST tank space shortfall in this time period.

The modifications to the waste retrieval facilities will consist of expanding the size of the building to enable the installation of additional storage capacity and increasing the capacity of the 150 -Kgal storage tanks to $300 \mathrm{Kgal}$ in each of two waste retrieval facilities. The net result will be an additional $1800 \mathrm{Kgal}$ of storage.

The cost estimate for this option is presented in Table 4-18.

Table 4-18. Cost Estimate for Option 4.8B - Waste Retrieval Facilities

\begin{tabular}{|l|c|}
\hline \multicolumn{1}{|c|}{ Activity Description } & Cost (SK) \\
\hline Obtain perm itting and regulatory approval & 0 \\
\hline Prepare waste retrieval facilities design & 0 \\
\hline $\begin{array}{l}\text { Perform waste retrieval facilities procurement and construction for } \\
\text { increased capacity }\end{array}$ & 69,000 \\
\hline Conduct startup and testing & 0 \\
\hline Option Total & $\mathbf{6 9 , 0 0 0 ^ { * }}$ \\
\hline
\end{tabular}

* The costs for this activity reflect a delta or "adtitional" cost for only the expanded scope. The expanded scope for each waste retrieval facility includes increasing the capacity of the 150-Kgal storage tanks to $300 \mathrm{Kgal}$ each

Based on the estimated $1800 \mathrm{Kgal}$ in Section 4.8 .3 .1 , the cost is $\$ 38.33 / \mathrm{gal}$.

The River Protection Project baseline presently includes $\$ 313,000 \mathrm{~K}$ to design and construct two waste retrieval facilities.

The cost estimate is based on the following assumptions:

a. The scope of this option will become part of the original design requirements document for the waste retrieval facilities that will result in a minimal cost increase to the project.

b. The original waste retrieval facilities requirements, other than volume, are sufficient for this option.

c. The project is of medium complexity based on using standard technologies for the storage tank in a radioactive/hazardous environment. 


\section{Option 4.8C-Small Modular Tanks for Storage}

The cost for the components and installation of a modular storage facility for $300-\mathrm{ft}^{3}$ stainless steel tanks was estimated. The tanks will be filled at the SST retrieval site by either retrieving the waste as a "dry" material or sluicing and drying the waste. For this option, the retrieval will use a similar method to the retrieval of CH-TRU. The modular storage facility will meet RCRA storage requirements because the $300-\mathrm{ft}^{3}$ tanks (primary containment) are placed into steel-lined culverts (secondary containment) fitted with conductivity type leak detection. A modular facility for the above grade storage of $300-\mathrm{ft}^{3}$ liners will be designed, constructed, tested, and turned over to tank farm operations for beneficial use. The modular storage facility will consist of a concrete slab, precast concrete culverts with steel liner with leak detection, cover blocks for the culverts, a crane for moving the waste liners, and a Butler building for protection from the elements. The concrete culverts will be close packed in a staggered configuration, which will enhance the shielding of the waste and shielding of each culvert will be supported by its neighbors.

Designing the facility to hold 500 waste tanks will add $1 \mathrm{Mgal}$ storage capacity. The facility will be unmanned. When a waste tank is to be added or removed from the facility, a transport will approach the facility. A crane operator and health physics technicians (HP tech) will meet the driver. The crane operator, driver and HP tech(s) will be in a shielded building while the crane is used to move the waste tank from the cask on the transport vehicle and places it in a culvert. Once the waste tank is in place, the crane operator will put a cover on the culvert and secure the crane. The crane operator, transport driver, and HP tech(s) will then leave the facility. Each conerete culvert/liner will have leak detection to remotely signal the operator that a waste tank is leaking.

The cost estimate for this option is presented in Table 4-19.

Table 4-19. Cost Estimate for Option 4.8C - Small Modular Storage

\begin{tabular}{|l|c|}
\hline \multicolumn{1}{|c|}{ Activity Description } & Cost (SK) \\
\hline Design and procurement of transportation casks & 5,000 \\
\hline Butler building & 500 \\
\hline Concrete pad & 1,500 \\
\hline Crane & 1,000 \\
\hline Precast concrete culverts with lids & 3,000 \\
\hline Culvert liners & 1,000 \\
\hline 300-ft ${ }^{3}$ stainless steel tanks & 7,000 \\
\hline Instrumentation and control & 2,500 \\
\hline Engineering & 2,000 \\
\hline Permitting & 4,000 \\
\hline Project management & 1,000 \\
\hline Option Total & $\mathbf{2 9 , 0 0 0}$ \\
\hline
\end{tabular}

* This cost does not include the cost for the transportation vehcle to move the $300-\mathrm{ft}^{3}$ tank from the SST to the modular storage facility, the cost associated with retrieval of the SST waste into the tanks, the cost of transporting the tanks from the SST to the modular storage facility, or moving the tanks from the modular storage facility to a DST of mixblend facility. 
Based on the estimated $1,000 \mathrm{Kgal}$ in Section 4.8 .3 .1 , the cost is $\$ 29 / \mathrm{gal}$.

This cost estimate is not budget grade but is for scoping purposes only.

\subsubsection{Schedule}

\section{Option 4.8A - Compliant Bladder in a Lined Basin}

The evaluation and implementation of option $4.8 \mathrm{~A}$ will include the development $\mathrm{research}$ for compatible liner material, design of the facility, design/construction of pretreatment system, new permitting/licensing, modification of authorization basis, procurement/construction of system. and development of operating procedures. The time to implement this option would be approximately 7 years. With the current limitations on starting new projects, the earliest the space in this option could be available would be 2021 .

\section{Option 4.8B - Waste Retrieval Facilities Storage}

The evaluation and implementation of option $4.8 \mathrm{~B}$ will include design of the facility, design of infrastructure, permitting/licensing, modification of authorization basis, procurement and construction of system and development of operating procedures. The time to implement this option would be approximately 7 years. With the current limitations on starting new projects, the earliest the space in this option could be available would be 2021 .

\section{Option 4.8C - Small Modular Tanks for Storage}

The evaluation and implementation of option $4.8 \mathrm{C}$ will include evaluation of methods of retrieving waste from SSTs, design of the facility, evaluation/design/modification of transportation components, permitting/licensing, modification of the authorization basis, procurement and construction of the facility, and development of operating procedures. The time to implement this option would be approximately 4 years. With the current limitations on starting new projects, the earliest the space in this option could be available would be 2018 .

\subsubsection{Feasibility Considerations}

Additional considerations for the feasibility of utilization of double-contained surface storage are discussed in the following. Tables 4-20 through 4-22 provide summary assessments for the use of a compliant bladder in a lined basin, use of expanded capacity in the waste retrieving facilities, and the use of small modular tanks for storage. 
RPP-7702, Rev. 1

Table 4-20. Feasibility Considerations for Option 4.7A Compliant Bladder in a Lined Basin

\begin{tabular}{|l|c|c|c|}
\hline \multicolumn{1}{|c|}{ Criteria } & High Feasibility & Medium Feasibility & Low Feasibility \\
\hline Technical feasibility & & & $\mathrm{X}$ \\
\hline Environmental risk & & $\mathrm{X}$ & \\
\hline Health and safety risk & & $\mathrm{X}$ & $\mathrm{X}$ \\
\hline Maintainability and operability & & $\mathrm{X}$ & \\
\hline Environmental regulatory impacts & & $\mathrm{X}$ & \\
\hline Authorization basis impacts & & & \\
\hline
\end{tabular}

Table 4-21. Feasibility Considerations for Option 4.7B - Waste Retrieval Facilities

\begin{tabular}{|l|c|c|c|}
\hline \multicolumn{1}{|c|}{ Criteria } & High Feasibility & Medium Feasibility & Low Feasibility \\
\hline Technical feasibility & & $\mathrm{X}$ & \\
\hline Environmental risk & $\mathrm{X}$ & & \\
\hline Health and safety risk & $\mathrm{X}$ & & \\
\hline Maintainability and operability & $\mathrm{X}$ & & \\
\hline Environmental regulatory impacts & $\mathrm{X}$ & & \\
\hline Authorization basis impacts & $\mathrm{X}$ & & \\
\hline
\end{tabular}

Table 4-22. Feasibility Considerations for Option 4.7C - Small Modular Storage Tanks

\begin{tabular}{|l|c|c|c|}
\hline \multicolumn{1}{|c|}{ Criteria } & High Feasibility & Medium Feasibility & Low Feasibility \\
\hline Technical feasibility & $\mathrm{X}$ & & \\
\hline Environmental risk & $\mathrm{X}$ & & \\
\hline Health and safety risk & & $\mathrm{X}$ & \\
\hline Maintainability and operability & & $\mathrm{X}$ & \\
\hline Environmental regulatory impacts & $\mathrm{X}$ & $\mathrm{X}$ & \\
\hline Authorization basis impacts & & & \\
\hline
\end{tabular}

\section{a. Technical Feasibility}

For option $4.8 \mathrm{~A}$ to be viable, it will be necessary to combine a compliant bladder in a lined basin with another concept to remove cesium and solids from the tank waste. Two new processes to remove cesium and solids will need significant shielding and also be operated remotely. While these operations have been performed previously at the Hanford Site and elsewhere, they are relatively complex and are expensive compared to tank waste storage. The combined impact of two new systems decreases the technical feasibility of this option. The bladder material may also require development to meet the waste storage needs, which may require several years of development to meet compatibility requirements.

Option 4.8B is technically feasible because the waste retrieval facilities are planned for future use during SST retrieval but have not yet been designed or built. The designs are based on DCRTs and do not require new technologies. 
Option $4.8 \mathrm{C}$ is technically feasible because storage facilities have been designed and built at the Hanford Site which are similar but more complex than the visualized facility. Since the design concepts are based on existing facilities, no new technology would be required.

\section{b. Environmental Risk}

There will be some inherent increase in environmental risk due to the open-air nature of the secondary containment on Option 4.8A, even with the cesium removed from the waste. Even though the cesium would have been removed, the transuranic and strontium contents of the exposed waste would contribute significant risks due to the potential for dispersal of the waste.

There are no new environmental risks introduced by expanding the size of the planned facilities in option $4.8 \mathrm{~B}$.

There are no new environmental risks introduced by storing the waste in compliant storage as planned in option $4.8 \mathrm{C}$.

\section{c. Health and Safety Risk}

Storing tank wastes at a Liquid Effluent Retention Facility style basin with a compliant bladder should not pose any additional concerns for worker safety and health. However, only low dose, low solids content supernatant that has been treated at the waste retrieval facilities to remove cesium could be stored. The operation of the cesium removal system could add new health and safety risks due to the expected dose of the initially retrieved wastes.

Expanding tank waste storage at waste retrieval facilities will not pose any additional concerns for worker safety and health.

Storing the waste in modular waste tanks will require somewhat more handling and movement of the waste over the current baseline so there may be some additional concern for worker safety and health. Because the waste is currently stored dry, there are no additional health and safety concerns with dry materials in a modular storage facility. With the use of small size containers the impact of any problems would likely be reduced.

\section{d. Maintenance and Operability}

A Liquid Effluent Retention Facility style basin with compliant bladder option will be more difficult to maintain and operate than the Liquid Effluent Retention Facility. There would be additional equipment required to transfer the waste back to DSTs. Decontamination and decommissioning of the bladder will be difficult. Adding cesium removal to the waste retrieval facilities to support option $4.8 \mathrm{~A}$ will increase operational complexity. 
Option $4.8 \mathrm{~B}$ should be no more difficult to operate than the current plans for operating the waste retrieval facilities and should be very similar to present DCRT operations.

Option $4.8 \mathrm{C}$ modular storage facility will be somewhat more difficult to operate than the Central Waste Complex because in the Central Waste Complex most of the waste is contact handled, and would be approximately the same as operating the Canister Storage Building. Retrieval of SSTs is not included in the scope of this report, but the additional requirement of dry retrieval or drying sluiced waste will add complexity to SST retrieval. Planned retrieval of $\mathrm{CH}$-TRU waste requires sluicing the waste from the SSTs and then drying the waste and packaging in drums. The dose rate from most of the SST waste would preclude contact handling. It is assumed that the retrieval systems designed for $\mathrm{CH}-\mathrm{TRU}$ retrieval can be modified to allow retrieval of remote handled waste types. Remote handling will require additional shielding and systems that allow some connections to be remotely made and broken. Systems for remote or shielded connection have been designed and are in use throughout the DOE complex. A significant benefit to modular storage is the ability to provide the capability for additional blending of HLW feeds. Sampling of the waste in each tank would be desirable for blending. The retrieval systems do not include systems for record type sampling. Adding record sampling capability to retrieval systems would also increase the complexity of current or planned retrieval systems.

Transportation of similar and in some cases more hazardous materials than SST waste is routinely performed on Hanford Site roadways. Radioactive material transportation operations are well understood, and while these operations have not been included in the tank farm operations, implementing procedures exist for similar materials. For the purpose of this report, maintainability and operability of the transportation systems for transporting SST waste are assumed to be of the same order of magnitude as maintaining and operating current waste transfer systems.

\section{e. Environmental Regulatory Impacts}

Storing tank wastes at a Liquid Effluent Retention Facility style basin with a compliant bladder would be covered by a new TSD permit due to the required initial treatment of the waste.

Storing tank wastes at waste retrieval facilities would require minor modification to the existing tank storage permit or perhaps a new permit. However, there would be no increase in the permitting effort to achieve the increased storage capacity.

Storing tank waste in modular storage would require a new TSD permit. This permit should require the same level of effort as the permit for the waste retrieval facilities.

It is important to note that Ecology would likely have incentive to approve the permit for any of these options since the SST waste would be removed from non-compliant storage into compliant storage. 


\section{f. Authorization Basis Impacts}

Authorization basis amendments will be needed to implement option $4.7 \mathrm{~A}$ because of the relatively complex cesium and solids removal processes and bladder storage.

Authorization basis amendments would also be required for option 4.7B. However, there would be no new functions beyond present DCRT operations, and therefore, the amendments may be accomplished as part of the annual update.

Authorization basis amendments would be required for option $4.7 \mathrm{C}$. The amendments would include retrieval of the waste as a solid and transportation of the waste tanks over the road from the SSTs to the modular storage facility. The waste could be retrieved from the tanks as a liquid and dried at the SSTs before being put into the waste tanks. Drying could be done with a wiped film evaporator, concentrate dryer, or similar system. The $\mathrm{CH}$-TRU retrieval system includes sluicing the waste material and then drying and packaging the waste into drums. It is assumed that systems designed for retrieval of $\mathrm{CH}$-TRU can be modified for the remote handled waste types. The transportation cask and stainless steel tanks would be fitted with NucFil ${ }^{4}$ or similar filters for flammable gas release. Because the SSTs do not include active ventilation, passive ventilation is assumed in the modular storage facility.

\subsection{NEW DOUBLE-SHELL TANK}

\subsubsection{Description}

This option would create additional waste storage capacity by construction of DSTs similar to the existing design. These new tanks will meet state and federal regulations and will have a 50 -year design life. Each additional DST would increase available capacity by $1200 \mathrm{Kgal}$.

\subsubsection{Background}

This option is consistent with current program strategy of moving SST wastes to compliant DST storage. The tanks will be designed using lessons learned from the Waste Tank Safety Program, the Multi-Function Waste Tank Facility design (WHC-SD-W236A-ER-021, Multi-Function Waste Tank Facility Phase Out Basis), and the AQ and AT Farms designs. Additional waste storage capacity could be available for use in 2018-2025. The funding process is expected to take approximately 2 years; design and construction are expected to take 5 years. It is expected that savings would be obtained if a tank farm were built instead of individual tanks. The costs are based on a design that contained four tanks.

\subsubsection{Evaluation of Option}

\subsubsection{Additional Capacity (Gallons)}

Construction of each new DST will create $1200 \mathrm{Kgal}$ of additional capacity using an existing design.

\footnotetext{
${ }^{4} \mathrm{NucFil}^{\mathrm{w}}$ is a registered trademark of Nuclear Filter Technology, Golden, Colorado.
} 
RPP-7702, Rev. 1

\subsubsection{Cost}

The cost estimate for this option is presented in Table 4-23.

Table 4-23. Cost Estimate for Construct New Double-Shell Tanks Option (Based on Each One of at Least Four Tanks)

\begin{tabular}{|l|c|}
\hline \multicolumn{1}{|c|}{ Activity Description } & Cost (\$K) \\
\hline Obtain permitting and regulatory approval & 1,200 \\
\hline Design & 8,200 \\
\hline Procurement and Construction & 78,000 \\
\hline Startup and testing & 1,200 \\
\hline \multicolumn{1}{|c|}{ Option Total } & $\mathbf{8 8 , 0 0 0}$ \\
\hline
\end{tabular}

Based on the $1200 \mathrm{Kgal}$ volume in Section 4.9.3.1, the cost is $\$ 73.33 / \mathrm{gal}$.

The cost estimate is based on the following assumptions:

a. Adjustments were made to the $\$ 360 \mathrm{M}$ advanced conceptual design cost estimate of Project W-236A, Multi-Function Waste Tank Facility, a four-tank facility (WHV-SD-W236A-ER-021).

b. The Project W-236A estimate is used as a basis without detailed evaluation.

c. An escalation factor of $17.5 \%$ (about $2.2 \%$ year) was used to calculate past cost to present (2009) cost.

d. Weather enclosure for the tank farm was deleted from the Project W-236A estimate.

e. Mixer pumps are not used and were deleted from the Project W-236A estimate.

f. Tanks are constructed of carbon steel instead of $304 \mathrm{~L}$, stainless steel.

g. Modification of the Environmental Impact Statement is required.

h. A tank farm containing four tanks, the same as Project W-236A, was used as the basis for the cost of one tank. Additions of less than four tanks are likely to cost more per unit of volume.

This cost estimate is not budget grade but is for scoping purposes only.

\subsubsection{Schedule}

The evaluation and implementation of this option will include updating the design, changes to licensing/documentation, and construction. The time to implement this option would be in approximately 7 years. With the current limitations on starting new projects, the earliest the space in this option could be available would be 2021 .

\subsubsection{Feasibility Considerations}

Additional considerations for the feasibility of constructing new DSTs are discussed in the following. Table 4-24 provides the summary assessment of these considerations. 
RPP-7702, Rev. 1

Table 4-24. Feasibility Considerations for Construct New Double-Shell Tanks Option

\begin{tabular}{|l|c|c|c|}
\hline Criteria & High Feasibility & Medium Feasibility & Low Feasibility \\
\hline Technical feasibility & $\mathrm{X}$ & & \\
\hline Environmental risk & $\mathrm{X}$ & & \\
\hline Health and safety risk & $\mathrm{X}$ & & \\
\hline Maintainability and operability & $\mathrm{X}$ & & \\
\hline Environmental regulatory impacts & & & \\
\hline Authorization basis impacts & $\mathrm{X}$ & $\mathrm{X}$ & \\
\hline
\end{tabular}

a. Technical Feasibility

Construction of new DSTs is technically feasible based on previous engineering, construction, and operations experience. Detailed analysis of previous conceptual design estimates for DST construction is warranted and has the potential to reduce the cost per gallon derived from cost estimates for the Multi-Function Waste Tank Facility. For example, the River Protection Project plans to build $1500 \mathrm{Kgal}$ of LAW feed storage capacity at the WTP for $\$ 43 \mathrm{M}$.

\section{b. Environmental Risk}

New DSTs would be constructed per the requirements of Washington Administrative Code 173-303-640 (4)(e)(iii) that double walled tanks be designed as an integral structure (i.e, an inner tank completely enveloped within an outer shell) and be provided with a built-in continuous leak detection system. Operation of new DSTs would incur minimal incremental environmental risk; however, additional DSTs will result in an increase in closure costs for the Hanford Site.

\section{c. Health and Safety Risk}

The construction of new DSTs is a major construction activity that presents industrial safety hazards commensurate with other projects of this magnitude. No additional health risk to the public is expected from construction of new DSTs.

\section{d. Maintainabilitv/Onerability}

Additional maintenance or operational expense is incurred for the routine operation of additional DSTs. The maintenance and operational activities are similar to current activities, although the newer DSTs are likely to be subject to fewer equipment failures.

\section{e. Environmental Regulatorv Impacts}

Construction of new DSTs would require a change to the RCRA Part B permit to incorporate the new facilities. In addition, supplemental National Environmental Policy Act of 1969 (NEPA) documentation would be needed. Significant public comments would be expected. 


\section{f. Authorization Basis Impacts}

Construction of new DSTs would require an amendment to the tank farm authorization basis (RPP-13033, HNF-SD-WM-TSR-006) to incorporate the new facilities. However, this would not involve new processes.

\subsection{CONSOLIDATE WASTES IN SINGLE-SHELL TANK SYSTEM}

This alternative will be addressed in a separate study.

\subsection{DELIST WASTE AND SHIP TO WASTE ISOLATION PILOT PLANT}

This option is included in ORP-11242 for select B and T Farm tanks. In the case of the B and T Farm tanks, the waste can be packaged as CH-TRU. It is anticipated that drums of the waste will have contact dose rates less than $200 \mathrm{mrem} / \mathrm{hr}$. The retrieval, handling, and packaging of the CH-TRU waste will be done independently from the DSTs.

The CH-TRU from the select B and T Farm tanks identified in the baseline for ORP-11242 is assumed to be shipped to the Waste Isolation Pilot Plant (WIPP) and will have no impact on DST space.

Previous system plans have suggested that some SST waste might also be determined to be remote handled transuranic waste (RH-TRU). ORP-11242 has not identified tanks as candidates for shipment to WIPP as RH-TRU.

\subsection{DELAY CAUSTIC ADDITION TO THE DOUBLE-SHELL TANKS}

Work is ongoing to evaluate the current DST corrosion specification. If successful, the modified specification would allow the $\mathrm{pH}$ in DSTs to be as low as 10 versus the current specification of $\mathrm{pH}$ 14. Changing the specification would allow caustic additions to be delayed or perhaps eliminated. It is unlikely that this change in specification would result in significant tank volume as compared to other options discussed. 


\section{OPTIONS EVALUATED LESS LIKELY TO ALLEVIATE 2018-2025 TANK SPACE SHORTAGE}

In addition to the options considered likely to increase waste storage capacity during 2018-2025, several options were identified for evaluation during the preparation of Rev. 0 that have the potential of increasing storage capacity in the longer term. Although these options may require longer to develop and implement, successful deployment would reduce the need for additional DST storage space. Given the implementation time and the greater uncertainties associated with these options, cost estimates and schedules were not developed.

The long-term options are categorized as follows:

a. Options that save or add to existing waste storage capacity.

b. Options for enhanced treatment alternatives at the WTP.

c. Options to store and or treat waste outside the present system.

d. Options that were evaluated and determined to be nonviable.

\subsection{LONG-TERM OPTIONS TO STORE AND/OR TREAT OUTSIDE PRESENT SYSTEM}

These options increase available waste storage capacity through storage and/or treatment in facilities outside the current DST and WTP system. Options considered include the following:

a. Separate nonhazardous, nonradioactive fractions.

b. Use evaporators for chemical reactor space.

c. Deploy low volume capacity processing units.

\subsubsection{Separate Nonhazardous, Nonradioactive Waste Fractions}

\subsubsection{Separate Nonradioactive Salt from the Waste}

\section{Description}

The option considers the use of modular ex-tank processing units to remove a significant volume of nonradioactive salt from SST or DST waste. The salt stream would then be converted into a material suitable for disposal or aboveground interim storage, thereby creating available DST space.

\section{Background}

Waste storage capacity is created in the DST system by extracting a large volume of nonradioactive salts, considered LAW. The salts would be converted into a nonhazardous material and/or immobilized into a nonhazardous material for disposal. Removal of the 
nonradioactive, nonhazardous materials from SSTs results in a smaller volume of waste requiring transfer to the DST system.

The unique merit of this concept is that nonradioactive chemicals comprise the majority of the HLW volume in the DSTs and SSTs. Direet extraction of the nonradioactive species would create usable DST space. The approach is effectively a pretreatment process but differs significantly from the baseline pretreatment in that it selectively removes target radionuclides. In this concept, the nonradioactive salts are selectively removed in a manner conceptually similar to the waste evaporation to reduce waste volume.

\section{Evaluation}

The removed salt must be declared incidental waste; that is, no longer HLW requiring storage in a deep geologic repository for successful deployment of this option. A clearly defined disposal pathway must be defined that meets regulatory requirements and achieves stakeholder acceptance. The extracted salt stream must have sufficiently low levels of radionuclides and will need to be converted into an acceptable nonhazardous material to allow disposal.

Candidate technologies to extract the salt with negligible radionuclides have been investigated. These technologies can be broadly grouped under the topics of erystallization, electrochemical separation (salt splitting for example), and solvent extraction. Both the crystallization and electrochemical technologies have had significant development and have been proven at the laboratory bench scale with actual waste, but technical issues for operational implementation remain. The solvent extraction approach for this specific purpose is relatively new.

One issue with the crystallization technology involves the fate of sulfate, which is one of the chemical species limiting the LAW glass waste loading. Previous crystallization studies focused on acidifying waste and then conducting crystallization because testing showed much better radionuclide separation with acidified waste. The formation of gels with alkaline waste was also avoided. However, it may be necessary or preferable to do crystallization with alkaline wastes to additionally crystallize sulfate salts. The ability to achieve necessary radionuclide removal and avoid gelling will require development.

This approach is an alternative treatment, storage, and/or disposal option for some of the LAW fraction. Accordingly, the regulatory requirements, issues, and drivers are the same as those that apply to the current baseline for LAW glass. The current baseline employs ex-tank pretreatment in a facility to separate HLW feed into a HLW stream containing essentially all of the radioactivity and $\mathrm{L} \mathrm{AW}$ fraction that has key radionuclides removed.

Finally, the waste is a listed hazardous waste, as defined by RCRA, and will need to be delisted, which will require that the waste be rendered nonhazardous and meet LDRs. 


\subsubsection{Separate Low-Activity Waste from High-Activity Waste}

\section{Description}

In this concept, the SST wastes would be retrieved from the tanks and would be treated in low capacity systems to separate the wastes. A LAW stream would be stabilized for interim storage or disposal; and a low-volume, high-activity waste stream would be transferred to the DST system for future vitrification. This differs from the option in Section 5.1.1.1, which only removes nonradioactive components. In this option, the removed stream contains low activity radionuclides, as well as nonradioactive components.

\section{Background}

Saltcake, composed primarily of sodium nitrate and sodium hydroxide, would be dissolved and the aqueous solution would be sent to a separation process where the sodium and nitrate would be removed. Several technologies are being developed that could be used including the following:

a. Steam reforming to destroy the nitrate via reduction. The sodium is tied with clay that is added to the process resulting in an inert solid and a clean salt. Both resulting wastes should be suitable for low-level waste disposal;

b. Electrochemical nitrate destruction followed by electrochemical/membrane technology for sodium removal;

c. Electrochemical nitrate destruction followed by sodium removal using solvent extraction; or

d. Clean salt, a precipitation process.

Sludges, undissolved solids, and the residual waste stream after nitrate and sodium removal would be sent to the DSTs. The recovered sodium could be converted to a form for use later as a processing chemical (such as sodium hydroxide), for storage as a stabilized LAW for future immobilization, or for immediate disposal as a glass, grout, or clay mineral. The removed sodium would still be contaminated and would need to be managed as a radioactive and possibly hazardous waste.

\section{Evaluation}

The technologies for removing the sodium and nitrate from the wastes are at various stages of development and would need additional development and demonstration before implementation. The forms selected for management of the wastes would need to be selected and qualified as appropriate. New facilities would need to be designed, constructed, and permitted.

In concept, this is very similar to the project baseline strategy, but could use small "packaged" treatment units, to create alternative LAW forms of much of the waste volume, while following the same pathway for the HLW fraction. The environmental and regulatory activities would need to be further developed. 
RPP-7702, Rev. 1

\subsubsection{Use of Evaporators for Chemical Reactor Space}

\section{Description}

This alternative considers the use of existing containment facilities to avoid building new facilities.

One obstacle to the use of small-scale processing to reduce the volume of retrieved waste and the volume of waste ultimately converted into glass is the cost of construction of new containment for radioactive waste processing facilities.

\section{Background}

Evaporators were built inside suitable containment buildings. Use of the 242-S Evaporator building or unused space in the operational 242-A Evaporator could be used for small-scale waste processing facilities.

During site operations, evaporator facilities were built to reduce the volume of waste placed into storage. In the 200 East Area, the 242-A Evaporator is operational. In the 200 West Area, the $242-\mathrm{S}$ Evaporator is idle and likely will not be operated as an evaporator again. The building is intact and ventilation is operational.

Successful use of existing available evaporator building space for small-scale processing of retrieved waste could facilitate the reduction of waste volume, thereby making the existing DST capacity capable of accommodating a greater percentage of retrieved waste.

\section{Evaluation}

There are a number of technical issues that affect the use of evaporator buildings to contain chemical reactors. These include, but are not limited to, the following:

a. The installation of processes in 242-A Evaporator would need to be planned so as not to interrupt evaporator operations.

b. Access to evaporator building containment areas is typically limited to cover blocks on the roof.

c. Existing lines into and out of the 242-S Evaporator are likely to be unusable, requiring replacement for connection to the tank farms.

d. The ventilation system acceptable for the idle 242-S Evaporator facility would require refurbishment to increase reliability.

Changes to the 242-A Evaporator or use of the 242-S Evaporator building require regulatory treatment permits, possible upgrades to ventilation and monitoring systems, and updates to the existing authorization basis (RPP-13033). 


\subsubsection{Deploy Low Volume Capacity Processing Units}

This option is the deployment of a skid-mounted low-volume-capacity processing unit to treat tank waste thereby creating the opportunity for additional SST waste retrieval. The unit could be deployed to process DST waste for volume reduction or to process SST waste as it is retrieved. Two processes that could be deployed on small skid-mounted units include, but are not limited to the following:

a. Separation of nonhazardous nonradioactive fractions from the waste.

b. Waste vitrification.

\subsubsection{Separation of Nonhazardous Nonradioactive Fractions}

\section{Description}

This option involves separation of nonhazardous nonradioactive fractions from the SST waste. The volume of the remaining hazardous radioactive waste to be stored and vitrified could be significantly reduced. The Tanks Focus Area, a DOE-sponsored technology development program, is supporting development of skid-mounted systems capable of removing or recycling the sodium and nitrate in dissolved saltcake streams to significantly reduce the volume of waste to be sent to the DST tanks. This has a potential large cost saving because of the following:

a. DST tank capacity required to handle the waste would be minimized.

b. Low-level waste vitrification costs could be reduced if a fraction of the waste can be separated for disposal as low-level waste.

c. Disposal costs could be reduced further if supernate can be cleaned up sufficiently for disposal through the Liquid Effluent Retention Facility/Effluent Treatment Facility.

\section{Background}

The Tanks Focus Area has been investigating potential waste treatment technologies for the past two decades. Processes that have been identified as potentially viable for deployment as a small operating unit include the following:

a. Electrochemical nitrate destruction followed by electrochemical caustic recycle, as demonstrated by the Savannah River Technology Center and by Pacific Northwest National Laboratory.

b. Electrochemical nitrate destruction followed by caustic recycle using solvent extraction.

c. Clean Salt, a precipitation process developed at the Hanford Site.

d. Studsvik ${ }^{\top M^{3}}$ steam reforming to destroy the nitrate via reduction.

The electrochemical nitrate destruction has been demonstrated at Savannah River Technology Center in large-scale equipment, and the process cell is available for Hanford use. In discussions

${ }^{5}$ Studsy $k^{T M}$ is a trademark of Studsvik, Erwin, Tennessee 
with a private company, Electrosynthesis ${ }^{\mathrm{TM}},{ }^{6}$ and Savannah River Technology Center, a skidmounted process was proposed. A project outline was been drafted by the Tank Focus Area and studies continue. There is a potential problem with the caustic recycle because the technology requires a membrane that complicates the maintenance requirements for this process.

When nitrate is destroyed via electrochemical system, a large volume of caustic is generated. This byproduct can be recovered and used for caustic addition to tanks or used for sludge washing. The stream also could be treated directly with a grout former to make a low-level waste form.

Electrochemical nitrate destruction followed by solvent extraction is a promising technology. The process maintains low reagent inventory, and is easy to flush for maintenance. The solvent extraction process appears promising but has not yet been demonstrated.

Addition of the Clean Salt Process to the baseline operating plan would divert most of the L.AW stream to a new stream, nonradioactive salt. The Clean Salt Process does not address the HLW stream, which is low in sodium. It deals only with the LAW stream, either before or after cesium ion exchange, where sodium salts account for over $90 \%$ of the estimated 200,000 metric tons of waste (dry weight basis).

The LAW stream is acidified with nitric acid to $\mathrm{pH} 2$. The acid solution is filtered to remove traces of insoluble solids, which are routed to the HLW. The clarified solution is evaporated until sodium nitrate $\left(\mathrm{NaNO}_{3}\right)$ crystals form. The $\mathrm{NaNO}_{3}$ slurry is filtered. The filtrate, which contains the radionuclides, becomes the new salt-depleted $\mathrm{LAW}$ stream. The $\mathrm{NaNO}_{3}$ solids are washed with water or clean $\mathrm{NaNO}_{3}$ solution to remove contaminated interstitial liquid. The wash liquid is recycled to the evaporator, and the washed solids are recrystallized from water as often as required to reach the desired level of decontamination.

The Studsvik ${ }^{\mathrm{TM}}$ process is a complete process to treat the tank wastes. Low-level waste supernate is reacted with steam, a carbon source (a reducing agent and a fuel to keep bed temperature acceptable), and clay to tie up the sodium. The process operates at 550 to $650^{\circ} \mathrm{C}$. All of the anions are either destroyed (nitrate, oxylates, carbonates) or are scrubbed in the offgas (sulfates, chlorides, fluorides). The sodium is tied as sodium aluminasilicate, a solid nonleachable material suitable for disposal. The water is evaporated. The solids are collected as sodium aluminum silicate $\left(\mathrm{NaAlSiO}_{4}\right)$, and as a clean salt composed primarily of sodium sulfate $\left(\mathrm{Na}_{2} \mathrm{SO}_{4}\right)$. This salt can be sent to a low-level waste disposal facility. The process is operated at temperatures below that of an incinerator. Large volumes of gas are evolved which must be processed.

All of these technologies perform better with cesium removal before processing. Removal of cesium was demonstrated at the 1-gpm rate at Oak Ridge National Laboratory, and three processes are being demonstrated in a rigorous evaluation of competing technologies at the Savannah River Site. The most mature process is ton exchange. A column $4-\mathrm{ft}$ tall, $2 \mathrm{ft}$ in diameter, with a backup guard column will be sufficient to handle the Hanford low volume capacity processing unit requirements. This configuration is appropriate because it can fit in a

\footnotetext{
${ }^{6}$ Electrosynthesis ${ }^{\mathrm{TM}}$ is a trademark of Electrosynthesis Company, Inc, Lancaster, New York.
} 
shielded cask. It may also be possible to remove cesium in the waste retrieval facilities or in a $\mathrm{mix} / \mathrm{blend}$ facility.

\section{Evaluation}

The technology for separation of the nonhazardous, nonradioactive fraction from tank waste has been demonstrated on an experimental scale and would require significant additional development to be implemented in the proposed manner.

This alternative will add to maintenance or operational expense. Startup of new technology will present maintenance and operational challenges including an infrastructure for control, feed staging and handling, waste stream storage and recycle, and offgas treatment. This option may be more difficult to operate than the current option used. The units are small but since they are experimental, they will require operational supervision.

Assuming 5 years of operation, low volume capacity processing units such as described in this section would make approximately $1000 \mathrm{Kgal}$ of existing DST capacity available. A 1-gpm low volume capacity processing unit operating at $50 \%$ efficiency for 5 years would remove approximately $1000 \mathrm{Kgal}$ from the DSTs.

These technologies are experimental but have been successfully demonstrated experimentally on low-level waste; therefore, the safety issues should be understood. There is an environmental risk due to the experimental nature of this technology. Installation of a low volume capacityprocessing unit will require permitting, and because these technologies are experimental, the permitting issues may not be completely understood. Changes to the authorization basis (RPP-13033) will also be required.

\subsubsection{Small Mobile Vitrification Plant}

\section{Description}

Vitrification is a waste treatment process that turns mixed waste into glass. It provides a stable, nonleaching waste glass product suitable for long-term storage. Vitrification also reduces the volume of waste by evaporating water, oxidizing organies into harmless gases, and consolidating metals and other contaminants into nonporous solids. Issues with vitrification include transporting waste to vitrification facilities, increasing the risk of worker exposure and wasterelated transportation incidents. Additionally, vitrification facilities can be expensive to construct.

\section{Background}

One possible solution to issues associated with vitrification for some of the waste streams is a modular, transportable vitrification system for mixed waste called the Transportable Vitrification System, which costs less than $\$ 5$ million. The Transportable Vitrification System was designed and fabricated by Envitco, Inc. of Toledo, Ohio, which has a U.S. patent pending. The Transportable Vitrification System was built to be moved from site to site to treat some of the DOE's low-level mixed waste streams. 
The first process step in the Transportable Vitrification System is mixing wastes with additives, such as sand, soda ash, borax, lime, or alumina, to promote the formation of a stable glass product. The mixture enters the Joule-heated melter, where currents passing between electrodes transform the waste mixture into a molten state. This process decomposes and dissolves inorganics and locks radioactive materials into the glass melt. The melter's offgas system treats any vapors evolved from the melt. The molten material is poured into steel containers as it is produced. After cooling, the containers of glass are stored for eventual disposal.

Moving the Transportable Vitrification System requires about 12 tractor-trailers for its modules including feed preparation, melter, offgas, control and services, and process laboratory. Transport and reassembly of the transportable vitrifieation system takes about 6 weeks. The Transportable Vitrification System is designed to produce 300 pounds of glass per hour (depending on the type of waste) and to process wet, dry, and slurried waste.

\section{Evaluation}

This technology would have to be used in conjunction with a cesium removal process to provide low-level waste to the melter. The cesium would be sent to the WTP. This option is not a replacement to the WTP, because the Transportable Vitrification System could not handle the HLW fractions nor does it have enough throughput capacity.

Assuming 5 years of operation, the Transportable Vitrification System, a 1-gpm unit operating at $50 \%$ efficiency for 5 years would remove approximately $1000 \mathrm{Kgal}$ from the DSTs or from SSTs (via waste receiver tanks). It, therefore, would make approximately $1000 \mathrm{Kgal}$ of existing DST capacity available.

The mobile vitrification process unit would require a significant development program to implement. The technology is experimental but has been successfully demonstrated on low-level waste; therefore, the safety issues should be understood. There is a possible new environmental risk due to the experimental nature of this technology. The process will require permitting. Because these technologies are experimental, the permitting issues may not be completely understood. Installing the processing unit will also require changes to the authorization basis (RPP-13033).

This alternative will add to maintenance and operational expense. Startup of new technology will present maintenance and operational challenges including an infrastructure for control, feed staging and handling, waste stream storage and recycle, and offgas treatment.

\subsection{OPTIONS EVALUATED AND DETERMINED TO BE NONVIABLE}

Several options were identified in the workshops as having potential to increase available tank capacity. After evaluation, the following options were determined to be nonviable:

a. Place liners in SSTs.

b. Postpone deactivation of facilities.

c. Use existing facilities at Energy Northwest. 


\subsubsection{Place Liners In Single-Shell Tanks}

\section{Description}

This option considers deployment of liners in SSTs to provide double containment of the waste.

\section{Background}

The SSTs were built with a single primary steel tank that is surrounded with concrete. Leaks to the environment have resulted from failed steel liners. Installation of at least one liner in the sound tanks and two liners in the failed tanks would restore SSTs to a sound condition for waste storage, provide double containment, and meet the underlying requirement that waste be stored in RCRA compliant tanks. Liners based on a bladder design could be deployed through a tank riser.

\section{Evaluation}

There are serious technical issues that limit the feasibility of this option. The tanks would need to be emptied of waste to install the liner. Radiation levels and confined space concerns will require a remote installation approach.

Many of the SSTs contain significant equipment, either hanging from the risers or dropped into the waste in the tank during operations. Items that would obstruct remote installation of the liner would have to be removed before the liner is installed. In addition, the liner would have to be lightweight because of the overall size of the liner and be flexible enough to be remotely installed. No lightweight, flexible material has been identified that can withstand the elevated radiation fields for an extended period. Successful deployment of this option would require a research and development program to select and test the appropriate liner material.

Installation of leak detection, monitoring, and mitigation capability would need to meet the surveillance requirements for stored waste. Permitting for such a hybrid tank would be difficult.

\subsubsection{Postpone Deactivation Of Facilities}

\section{Description}

This option considers elimination or postponement of the receipt of waste resulting from deactivation of Hanford Site facilities, thereby allowing DST capacity to be redirected to storage of retrieved SST waste.

\section{Background}

Deactivation of Hanford facilities will generate liquid waste either directly from cleanup activities or from removal of stored waste. The deactivation of the B-Plant and PUREX facilities is completed. The deactivation of PUREX resulted in the transfer of $469 \mathrm{Kgal}$ of dilute waste to DSTs during 1995 and 1996. Deactivation of B-Plant resulted in the transfer of $103 \mathrm{Kgal}$ of dilute waste to DSTs between 1996 and 1998. 
The remaining Hanford facilities planned for deactivation that require transfer of wastes to DSTs are the Plutonium Finishing Plant, the $105-\mathrm{F}$ and $105-\mathrm{H}$ Basins, and the inactive miscellaneous underground storage tanks.

\section{Evaluation}

Deactivation of the Plutonium Finishing Plant, 105-F Basin, and 105-H Basin consumes minimal DST storage capacity when waste concentration using the 242-A Evaporator is included in the waste volume projections. Deactivation of these facilities is necessary to prevent liquid wastes from leaking to the environment and extending site cleanup.

\subsubsection{Use Existing Facilities at Energy Northwest}

\section{$\underline{\text { Description }}$}

This option would utilize existing facilities at Energy Northwest to store tank waste as an alternative to traditional buried underground storage tanks for increasing waste storage capacity.

\section{Background}

Two partially completed nuclear power plants, WNP-1 and WNP-4, are located on the Hanford Site near the Columbia Generating Station of Energy Northwest. It was suggested in the workshops that tank waste could be stored in these existing structures.

\section{Evaluation}

There are no large compliant storage facilities available. 


\section{OPTIONS ALSO CONSIDERED}

During the initial workshop for Rev. 0, a brainstorming session was held to elicit the participants' ideas to increase available DST space for storage of retrieved SST waste. Initially, only a brief description was requested. The ideas were reviewed to remove duplicates and combine alternatives. As part of the process, a number of options identified during brainstorming were eliminated because they did not meet required attributes. These ideas are summarized in the following as a record of the possibilities explored.

1. Separate aluminum to concentrate. Compounds of aluminum can create situations where concentrated solutions of tank waste crystallize and cannot be pumped. Removal of aluminum salts would increase the allowable specific gravity. The expected cost of treatment before the aluminum could be removed is thought to be quite high.

2. Cool waste until it contracts. This would require constant cooling and provide little additional capacity.

3. Heat tanks until they expand. This would cause structural damage and again provide little additional capacity.

4. Fill the DST annulus. This defeats the purpose of putting the waste into compliant storage, and provides little additional capacity.

5. Put barriers around SSTs (add double containment). The possibility of damage to the SSTs, the radiation exposure to workers when the tanks are excavated, and the probable costs make this an unlikely approach.

6. De-list tank waste. The amount of known hazardous constituents in the tank wastes makes this improbable.

7. Drill lateral drywells under the SSTs. This could provide an alternative method for leak detection; by itself, it does not provide additional tank capacity.

8. In-situ vitrification in SSTs. The waste would be immobilized but most likely would not meet LDR restrictions. Control of offgases during the process could create additional waste management issues.

9. Allow the SSTs to leak. This is unacceptable.

10. Account for released gas in SST. Accounting for released gas does not create additional tank space.

11. Evaporate dissolved ammonia in DSTs. Evaporating dissolved ammonia is not expected to yield significant additional tank capacity.

12. Pack particles closer together. This idea assumes that solids in the tanks are loosely packed and that there is a feasible way to cause them to take up less volume after 
13. Relax $99 \%$ retrieval constraint. This does little to change the need for tank capacity for the bulk of SST waste.

14. Use 244-AR or 244-CR Vault tanks. There is a small storage volume available in these tanks. The tanks are old and are slated for decommissioning.

15. Store waste in inactive transfer lines. Small volume to be gained; the lines are inactive for compliance and reliability reasons.

16. Do not flush active cross-site transfer lines. The flush water is removed when waste is run through the evaporator. In addition, the flush water is necessary to prevent line plugging, corrosion, and to maintain lower radiation levels in piping systems.

17. Grout and fill existing inactive buildings, e.g., Canyon Buildings, old reactors, old evaporators. These old facilities were not designed for disposal. Contamination and potential worker dose complicate any use of these facilities.

18. Put bladders in canyon building. This would be a subset of the previous item. This or addition of new tanks would be an integral part of use of any canyon facility for temporary waste storage. High dose areas in canyons make this idea impractical.

19. Fleet of rail cars. This idea is potentially costly because of acquisition of rail cars. Multiple problems with radiation control exist whether new doubled walled or older modified rail cars are used.

20. Retrieve low volume tanks first. This approach defers the capacity problem creating a larger problem later in the project. Additionally, this idea does not reduce risk nearterm.

21. Reconnect and fill the inactive miscellaneous underground storage tanks. The miscellaneous underground storage tanks have not been characterized. Each has small capacity. None meet RCRA standards.

22. Line and fill abandoned catch and fill boxes (i.e., diversion boxes). Diversion boxes are not normally double contained. Radiation conditions would cause most lining operations to be remote, and would be very expensive.

23. Fuel storage basins. The $\mathrm{K}$ Basins are too close to the river and are believed to have leaked in the past.

24. Market millions of milligram samples. This is not a viable option.

25. Use old tank farm designs. Tank farm facility designs were prepared in the $1980 \mathrm{~s}$ (e.g., AQ Farm). They were not designed to be RCRA compliant. The Multifunction 
Waste Tank Facility (W-236) is a newer design that was RCRA compliant (see Section 4.9)

26. Ship waste to Defense Waste Processing Facility or West Valley Processing Facility. Shielding during shipping would make this very costly even if Savannah River could take the waste.

27. Build multiple vitrification plants. Processing at dispersed regular vitrification plants is likely to be impractical and loses the economy of scale provided by the WTP.

28. Ship liquid waste to the High-Level Repository at Yucca Mountain, Nevada. Liquid waste is not an approved waste form for shipping or receipt.

29. Use abandoned Basalt Waste Isolation Project tunnels. Canister storage in Basalt Waste Isolation Project facility was not approved. The tunnels have been filled in.

30. Delist waste and ship to Waste Isolation Pilot Plant. This is an unlikely option given the permitting and Environmental Impact Statement for the Waste Isolation Pilot Plant and the present designation of tank waste.

31. Solidify and drum. This option would produce high radiation levels from untreated waste.

32. Fill submarine vaults. The submarine reactor compartments have already been carefully sealed for disposal.

33. Dry waste form in canister barrels and put back in SSTs for later retrieval. This idea is similar to some options presented in Chapter 5. However, this approach has an added complication of adding drums to old structures with little access and limits the ability to perform routine inspections.

34. Melt and pour directly into emptied SST. High temperatures could damage the concrete structures of the SST.

35. Evaporate low aluminum containing waste only/first. Selective retrieval sequence will account for waste content.

36. Postpone deactivation of inactive miscellaneous underground storage tanks. Deactivation is scheduled after 2011. 


\section{REFERENCES}

00-ORP-079, 2000, "Contract DE-AC06-99RL14047 - Configuration Control of Waste Feed Delivery Contents" (letter from H. L. Boston to M. P. DeLozier, CHG, September 8), U.S. Department of Energy, Office of River Protection, Richland, Washington.

7E310-94-024, 1994, "Evaluation of Specific Gravity Versus Gas Retention" (internal memorandum from D. A. Reynolds to N.W. Kirch, June 20), Westinghouse Hanford Company, Richland, Washington.

24590-WTP-ICD-MG-01-019, 2008, ICD-19-Interface Control Doctiment for Waste Feed, Rev 4, Bechtel National, Inc, Richland, Washington.

92-AMD-006, 1992, "Grout Vault 103 Upper Liner Acceptability," (letter from S. H. Wisness to D. B. Jansen, Ecology, January 27), U.S. Department of Energy, Richland Operations Office, Richland, Washington.

CHG-0007064 R, 2001, "Contract Number DE-AC27-99RL14047; Waste Volume Case Studies to Support the State of Washington Department of Ecology's Request" (Attachment: Draft Report on the Case Studies Requested by Ecology) (letter from D. I. Allen to A. B. Sidpara, ORP, February 16), CH2M HILL Hanford Group, Inc., Richland, Washington.

Ecology, EPA, and DOE, 1989, Hanford Federal Facility Agreement and Consent Order, as amended, Washington State Department of Ecology, U.S. Environmental Protection Agency, and U.S. Department of Energy, Olympia, Washington.

Elsevier, 1999, Land Disposal Restrictions Compliance Guide, Elsevier Science Inc., New York, New York.

HNF-1975, 1998, Immobilized Low-Activity Waste Interim Storage Facility, Project W-465 Conceptual Design Report, Rev. 1, Fluor Daniel Northwest Services, Richland, Washington.

HNF-3555, 1998, Evaluation of Waste Level Limits in Tank 241-SY-101, Rev. 0, Lockheed Martin Hanford Corporation, Richland Washington.

HNF-14755WRPS, 2009, Doctmented Safety Analysis for the 242-A Evaporator, Rev. 2-B, Washington River Protection Solutions LLC, Richland, Washington

HNF-EP-0182, 2009, Waste Tank Status Summary Report for March 31, 2009, Rev. 252, Washington River Protection Solutions LLC, Richland, Washington.

HNF-SD-WM-TSR-006, 2009, Tank Farms Technical Safety Requirements, Rev. 6-A, as amended, Washington River Protection Solutions LLC, Richland, Washington 
NEPA, 1969, National Environmental Policy Act of 1969, as amended, 42 USC 4321 et seq.

ORP-11242, 2009, River Protection Project System Plan, Rev. 4, DRAFT, U,S. Department of Energy, Office of River Protection, Richland, Washington.

Public Law 101-510, 1990, "Safety Measures for Waste Tanks at Hanford Nuclear Reservation," Section 3137 of National Defense Authorization Act for Fiscal Year 1991.

Resource Conservation and Recovery Act of 1976, as amended, 42 USC 6901 et seq.

RPP-6548, 2001, Test Report, 241-AZ-101 Mixer Pump Test, Rev. 1, CH2M HILL Hanford Group, Inc., Richland, Washington.

RPP-13033, 2009, Tank Farms Documented Safety Analysis, Rev, 3-D, Washington River Protection Solutions LLC, Richland, Washington

RPP-21216, 2008, Single Shell Tank Retrieval Selection and Sequence, Rev, 3A, CH2M HILL Hanford Group, Inc., Richland, Washington.

RPP-RPT-26040, 2006, Pairwise Blending of High-Level Waste, Rev. 0, CH2M HILL Hanford Group, Inc., Richland Washington.

WAC 173-303-640, Washington State Department of Ecology, "Dangerous Waste Regulations," Tank Systems, Washington Administrative Code, Olympia, Washington,

WHC-EP-0504, 1991, Soil Structure Interaction Analysis for Hanford Site 241-SY-101 DoubleShell Waste Storage Tanks, Westinghouse Hanford Company, Richland, Washington.

WHC-SD-W236A-ER-021, 1995, Multi-Function Waste Tank Facility Phase Out Basis, Rev. 3, Westinghouse Hanford Company, Richland, Washington.

WHC-SD-WM-SSP-005, 1994, Grout Facilities Standby Plan, Rev, 0, Westinghouse Hanford Company, Richland, Washington.

WHC-SD-WM-TI-755, 1996, An Analysis of Parameters Describing Gas Retention Release Behavior in Double-Shell Tank Waste, Rev. 0, Westinghouse Hanford Company, Richland, Washington. 


\section{APPENDIX A: LIFE CYCLE TRANSPORTATION AND DISPOSAL COST FOR HIGH-LEVEL WASTE CANISTERS}

Bases:

1. DOE/RW-0591, Analysis of the Total System Life Cycle Cost of the Civilian Radioactive Waste Management Program, July 2008.

a. Total system life cycle cost for Yucca Mountain (i.e., repository, transportation, balance of program) is $\$ 96,180$ million in $2007 \$$ s. 9p. vi, Table ES-10) [Note: costs for siting and construction of a second repository are not included]

b. The total system life cycle cost estimate is based on the acceptance, transport, and permanent disposal in the Yucea Mountain Repository (Repository) of all currently projected civilian and defense wastes estimated to be 122,100 Metric Tons Heavy Metal (MTHM) of Spent Nuclear Fuel (SNF) and HLW. (p.v)

c. Total quantity of commercial spent nuclear fuel to be accommodated is 109,300 MTHM (p. A-3, Table A-2). Capacity of a standard TAD canister will be approximately 9 MTHM (p. 14). Commercial spent nuclear fuel requires 12,145 TADs.

d. Total quantity of DOE/Naval spent nuclear fuel and high level waste to be accommodated is 3188 canisters of DOE/Naval spent nuclear fuel and 19,667 canisters defense HLW (p. A-5)

2. DOE/RW-0595, The Report to the President and the Congress by the Secretary of Energy on the Need for a Second Repository, December 2008.

a. ...studies indicate that the repository layout at Yucca Mountain can be expanded to accommodate three times, or more, the current statutory limit of 70,000 $\operatorname{MTHM~(p.~1)~}$

b. The Secretary of Energy recommends that, consistent with legislation that the Administration proposed in 2007 , Congress act promptly to remove the statutory limit of 70,000 MTHM for the Yucca Mountain repository...(p. 1)

3. For the purposes of this analysis it is assumed that all commercial spent nuclear fuel and DOE HLW and SNF will be placed in an expanded Yucca Mountain repository. The incremental cost of expanding the Yucea Mountain repository from the 70,000 MTHM statutory limit to the 122,000 MTHM is not included in the cost specified here.

4. DOE/RW-0573, Rev, 0, Yucea Mountain Repository Safety Analysis Report, June 2008.

a. For the purposes of this analysis, all DOE HLW and DOE/Naval SNF will be disposed in the 5-DHLW/DOE Codisposal waste package configurations (p. 1.5.2-4, Section 1.5.2.1.3)

b. For 19,667 canisters of DOE HLW and 3,188 canisters of DOE/Naval SNF the codisposal package results in 3934 TADs.

5. $\$ 96,180$ million (see $1 \mathrm{a})$ divided by $[12,145$ (see $1 \mathrm{c})+3934$ (see $4 \mathrm{~b})]$ TADs $=$ $\$ 6$ million/TAD. $\$ 6$ million per $5 \mathrm{HLW}$ canisters. Therefore, the cost per HLW canister is $\$ 6$ million $/ 5=\$ 1.2$ million per canister. 